Keywords: Gloveboxes,

Polymers, Gloves,

Dynamic Mechanical

Analysis,

Retention: 25 yrs-10561

SRNL-STI-2012-00070

\title{
Dynamic Mechanical Analysis Characterization of Glovebox Gloves
}

P.S. Korinko and Y. Breakiron

February 29, 2012

We Put Science To Work"

The Savannah River National Laboratory is managed and operated for the U.S. Department of Energy by

SAVAN NAH RIVER N UCLEAR SOLUTIONS, LLC

AIKEN, SC USA 29808 -SRNL.DOE.GOV 
This Page Intentionally Left Blank 


\section{SRNL-STI-2012-00070}

\section{Dynamic Mechanical Analysis Characterization of Glovebox Gloves}

Approvals:

Signature on file

$2-28-2012$

P. S. Korinko, Author

Materials Compatibility and Welding Technology

Signature on file

$3 / 11 / 2012$

Y. Breakiron, Author

Tritium Engineering Intern, Clemson University

Signature on file

$3 / 12 / 2012$

E. A. Clark, Technical Review

Materials Compatibility and Welding Technology

Signature on file

$5 / 10 / 2012$

T. M. Adams, Manager

Materials Compatibility and Welding Technology 


\section{Contents}

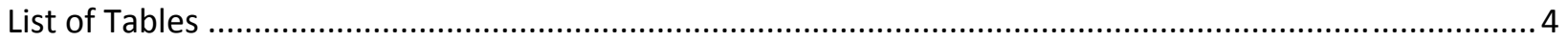

List of Figures

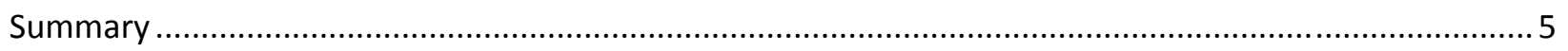

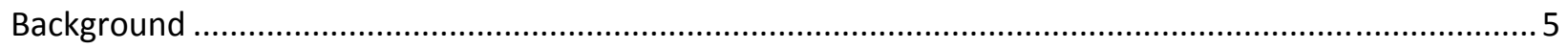

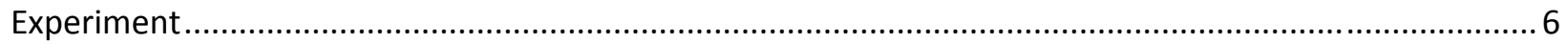

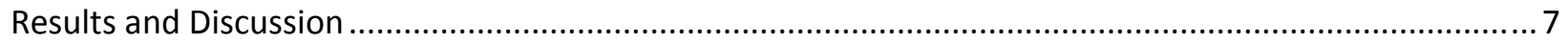

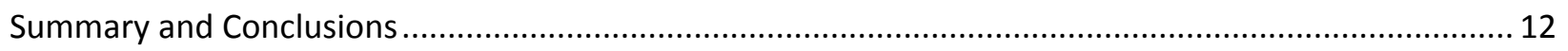

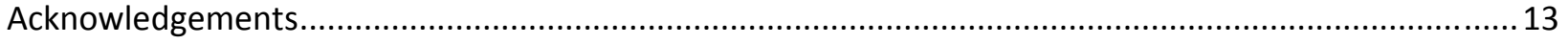

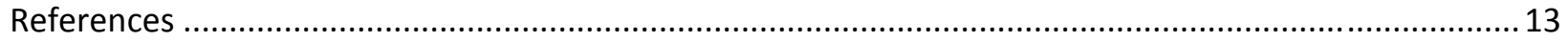

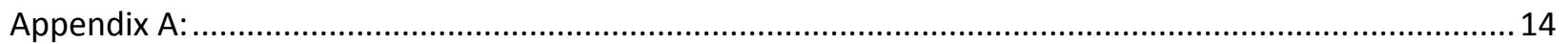

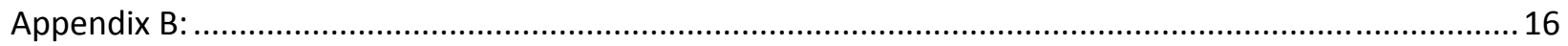

\section{List of Tables}

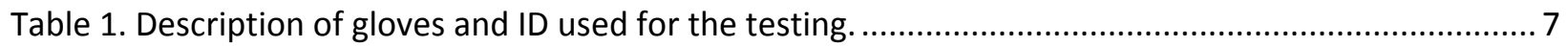

Table 2. Average measured Tg, Storage Modulus, and Tan $\delta$ for all the samples................................... 10

\section{List of Figures}

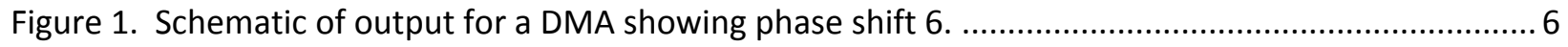

Figure 2. Schematic of DMA output indicating several physical changes in a polymer 6 ........................ 6

Figure 3. DMA results for a Guardian 15 mil Butyl rubber test at three loading frequencies (a) linear and

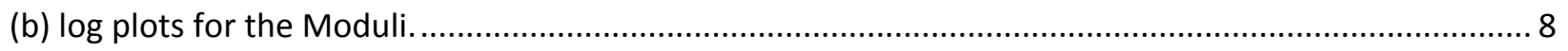

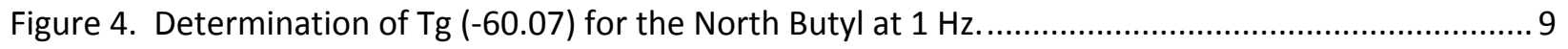

Figure 5. Graphical representation of the glass transition temperature gloves with single $T_{\mathrm{g}} \ldots \ldots \ldots \ldots \ldots . . . . .10$

Figure 6. North 30 mil Butyl exhibiting an increase in the loss modulus between 50 and $75^{\circ} \mathrm{C} \ldots \ldots \ldots \ldots . . . .11$

Figure 7. DMA results for Jung Butyl-Hypalon ${ }^{\circledR}$ with both Butyl and Hypalon overlays.......................... 12

Figure 8. DMA results for Jung Butyl-Viton ${ }^{\circledR}$ with both Butyl and Viton ${ }^{\circledR}$ overlays. ................................ 12 


\section{SRNL-STI-2012-00070}

\section{Dynamic Mechanical Analysis Characterization of Glovebox Gloves}

\section{Summary}

As part of the characterization of various glovebox glove material from four vendors, the permeability of gas through each type as a function of temperature was determined and a discontinuity in the permeability with temperature was revealed. A series of tests to determine the viscoelastic properties of the glove materials as a function of temperature using Dynamic Mechanical Analysis (DMA) was initiated. The glass transition temperature and the elastic and viscoelastic properties as a function of temperature up to maximum use temperature were determined for each glove material. The glass transition temperatures of the gloves were $-60^{\circ} \mathrm{C}$ for butyl, $-30^{\circ} \mathrm{C}$ for polyurethane, $-16^{\circ} \mathrm{C}$ Hypalon , $16^{\circ} \mathrm{C}$ for Viton , and $-24^{\circ} \mathrm{C}$ for polyurethane-Hypalon ${ }^{\circ}$. The glass transition was too complex for the butyl-Hypalon and butyl-Viton composite gloves to be characterized by a single glass transition temperature. All of the glass transition temperatures exceed the vendor projected use temperatures.

\section{Background}

Butyl rubber gloves are the gloves currently used for containment in gloveboxes at Savannah River Site (SRS) in the Tritium Facility. As part of an overall characterization task (ref 1-4), the permeation properties and rates at room temperature were determined in air and hydrogen (3). In an effort to expand the data to temperatures other than room temperature, a North Butyl 30 mil glove was tested at room, 50, and $75^{\circ} \mathrm{C}$. Based on thermally activated processes, it is expected that the permeation at elevated temperatures would scale linearly as logarithm of permeability versus reciprocal temperature, which is termed Arrhenius behavior. However, there appeared to be a non-linear discontinuity in the data plot of log permeability versus inverse temperature. Consequently, additional characterization was initiated using Dynamic Mechanical Analysis (DMA). Dynamic Mechanical Analysis is a technique where a small deformation is applied to a sample in a cyclic manner. This force application allows the material's elastic and viscoelastic response to stress, temperature, frequency and other values to be studied.

DMA measures stiffness and damping, which are reported as storage modulus (stiffness) and loss modulus and tan delta (damping). Because a sinusoidal force is applied, it is possible to express the modulus as an in-phase component, the storage modulus, and an out of phase component, the loss modulus, see Figure 1. The storage modulus, either $E^{\prime}$ or $\mathrm{G}^{\prime}$, is the measure of the sample's elastic behavior. The ratio of the loss to the storage is the $\tan$ delta $(\tan \delta)$ and is often called damping. It is a measure of the energy dissipation of a material.

Modulus values change with temperature and transitions in materials can be seen as changes in the $\mathrm{E}^{\prime}$ or tan delta curves. This includes not only the glass transition and the melt, but also other transitions that occur in the glassy or rubbery plateau, shown in Figure 2. These transitions indicate more subtle 
changes in the material. The samples were prepared and tested so that the properties from below the glass transition to the maximum use temperature were examined.

\section{Experiment}

Gloves from four manufacturers, North, Piercan, Jungitec, and Guardian, with compositions based on butyl, Hypalon ${ }^{\bullet}$, Viton ${ }^{\circledR}$, and polyrethane comprised the test matrix, shown in Table 1. Several thicknesses as well as composition variations were tested.

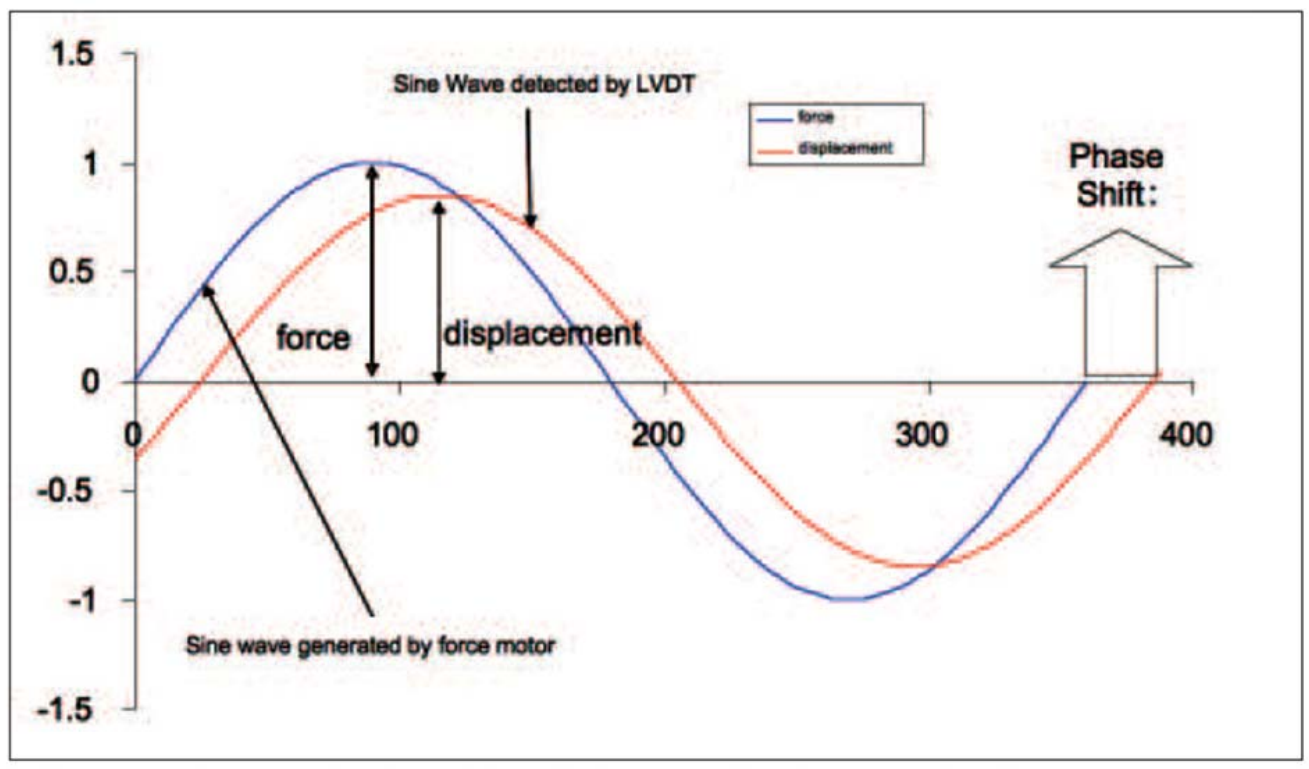

Figure 1. Schematic of output for a DMA showing phase shift 5.

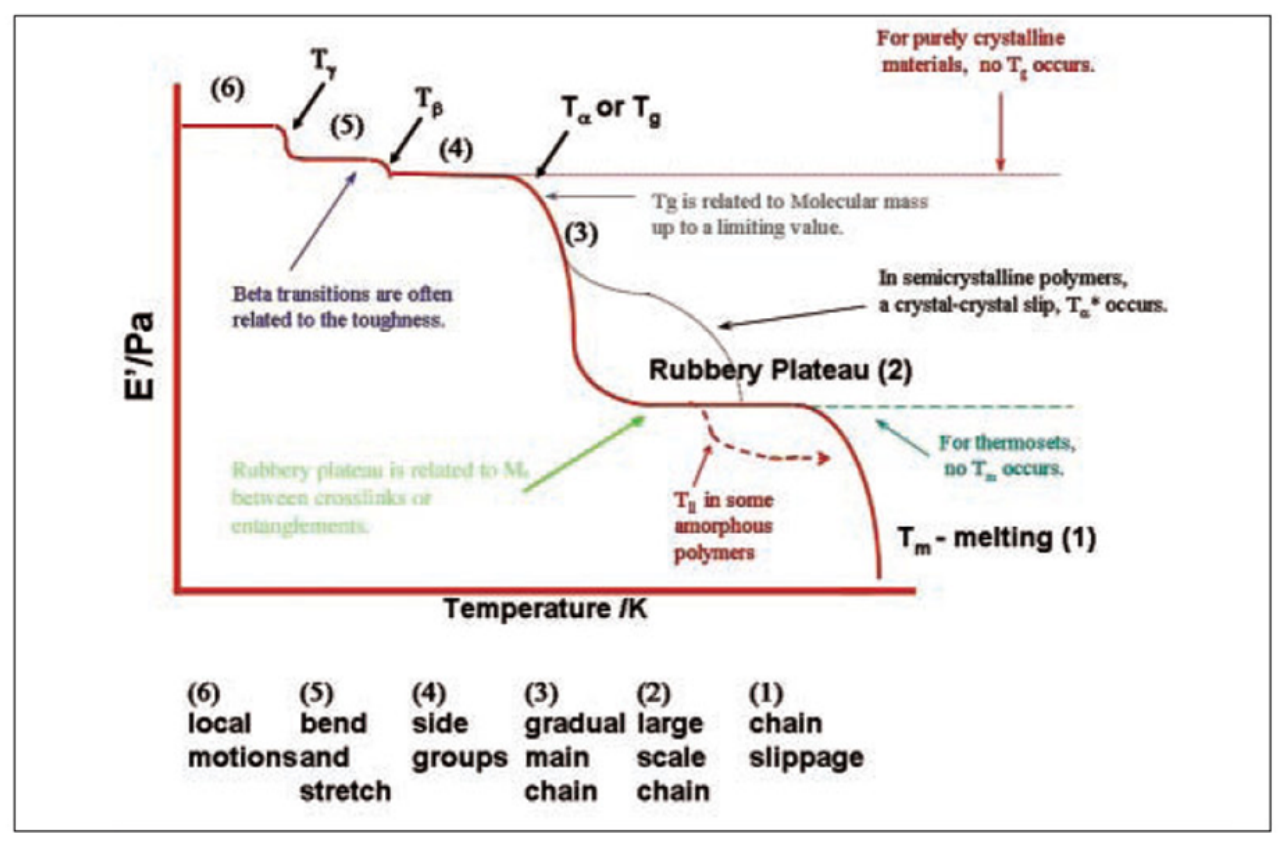

Figure 2. Schematic of DMA output indicating several physical changes in a polymer 5. 
A TA Instruments 2950 Dynamic Mechanical Analyzer was used for this study. It is a forced oscillation, non-resonant, constant amplitude instrument. A tensile clamp, or sample holder was used due to the thickness of the sample and broad temperature range of interest.

Rectangular test samples were cut from each glove. The samples were $6.4 \mathrm{~mm}\left(0.25^{\prime \prime}\right)$ wide and 44.4 $\mathrm{mm}\left(1.5^{\prime \prime}\right)$ long. Each sample being tested was installed on the tensile clamp. The test temperature was stabilized at the sub-ambient starting temperature $\left(-90^{\circ} \mathrm{C}\right.$ for most of the tests-but this was adjusted based on the observed $T_{\mathrm{g}}$ ), holding for ten minutes, and then increasing the temperature at $1{ }^{\circ} \mathrm{C} / \mathrm{min}$ to $120^{\circ} \mathrm{C}$ or the vendor recommended maximum temperature. The dynamic mechanical properties were continuously measured during the controlled heating. The TA 2980 has both electrical resistance heating and liquid nitrogen evaporative cooling using the Gas Cooling Accessory (GCA) and is controlled by the DMA software. The samples were loaded at frequencies of 1, 3, and $10 \mathrm{~Hz}$. Up to three replicate tests were run, depending on the fidelity of the data. The DMA amplitude was set to be 40 microns, and the force track was $125 \%$. The instrument was calibrated both at the beginning and the end of testing.

Table 1. Description of gloves and ID used for the testing.

\begin{tabular}{|c|c|c|c|c|c|c|c|}
\hline Vendor & Composition & $\begin{array}{l}\text { Thickness } \\
\text { (mils) }\end{array}$ & ID & Vendor & Composition & $\begin{array}{l}\text { Thickness } \\
\text { (mils) }\end{array}$ & ID \\
\hline North & Butyl & 15 & NB15 & North & Butyl & 30 & NB30 \\
\hline Piercan & Butyl & 15 & PB15 & Piercan & Butyl & 30 & PB30 \\
\hline Piercan & $\begin{array}{l}\text { Electrostatic } \\
\text { Discharge } \\
\text { Butyl }\end{array}$ & 15 & PESDB15 & Piercan & $\begin{array}{l}\text { Electrostatic } \\
\text { Discharge } \\
\text { Butyl }\end{array}$ & 24 & PESDB24 \\
\hline Guardian & Butyl & 15 & GB15 & Guardian & Butyl & 30 & GB30 \\
\hline Jung & $\begin{array}{l}\text { Butyl- } \\
\text { Hypalon }\end{array}$ & 27 & $\mathrm{JBH} 27$ & Jung & Butyl-Viton ${ }^{\circ}$ & 20 & JBV20 \\
\hline Jung & Viton ${ }^{\oplus}$ & 24 & JV24 & Jung & Viton $^{\circ}$ & 31 & JV31 \\
\hline Piercan & Polyurethane & 15 & PU15 & Piercan & $\begin{array}{l}\text { Polyurethane- } \\
\text { Hypalon }\end{array}$ & 20 & PUY20 \\
\hline Piercan & Hypalon & 25 & PY25 & & & & \\
\hline
\end{tabular}

\section{Results and Discussion}

The DMA results for Guardian Butyl at 15 mil thickness tested at 1, 3, and $10 \mathrm{~Hz}$ are shown in Figure 3. These results indicate consistent mechanical and physical property response over this frequency range. The increase in all three measured properties, storage modulus, loss modulus, and tan delta, with increasing frequency is expected and can even be used to account for time - temperature trade-offs, although that was not completed as part of this study. The glass transition temperature, $T_{\mathrm{g}}$, was obtained from the $1 \mathrm{~Hz}$ data for all the samples, a practice which is consistent with the approach taken in the literature. 


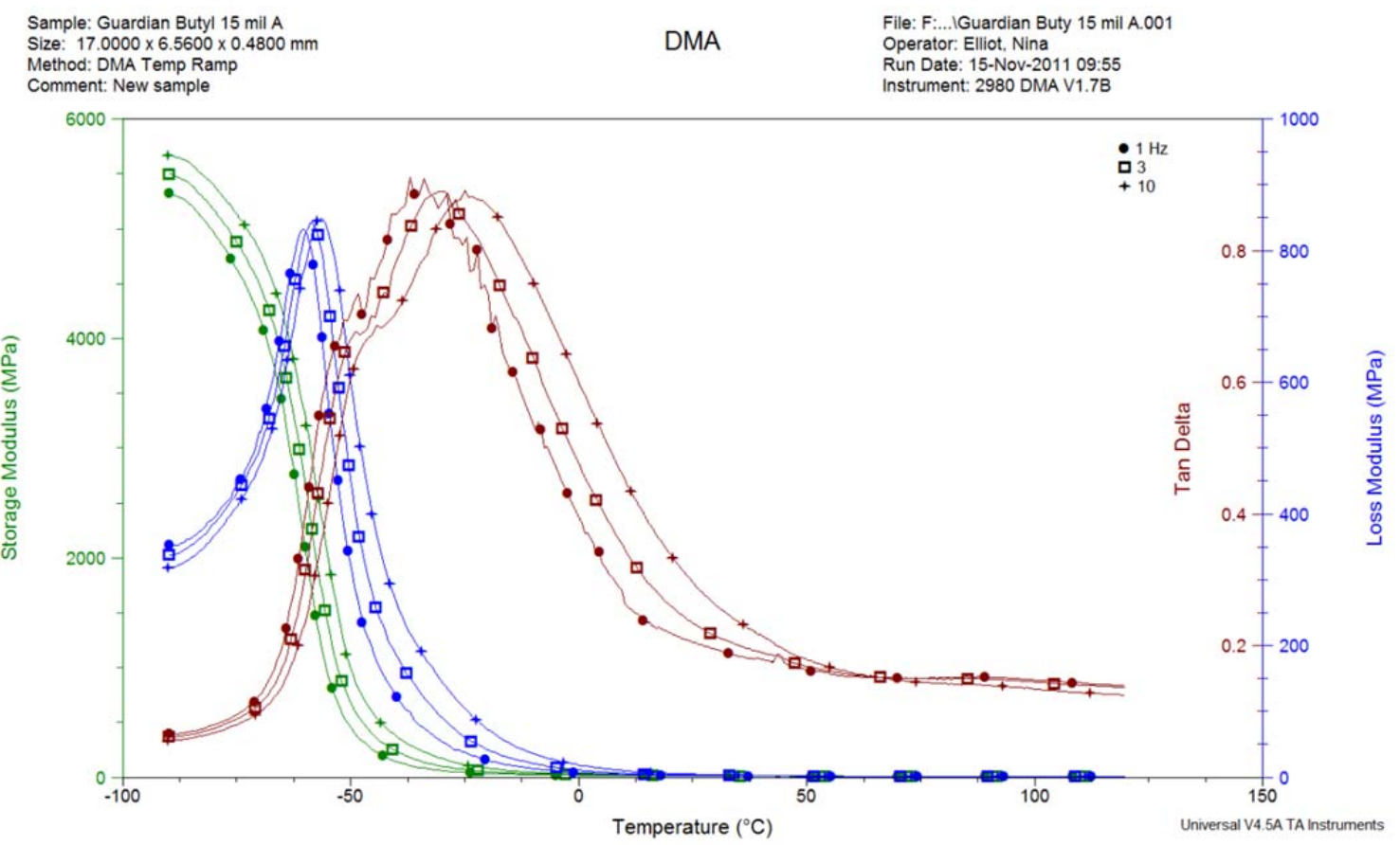

(a) Linear

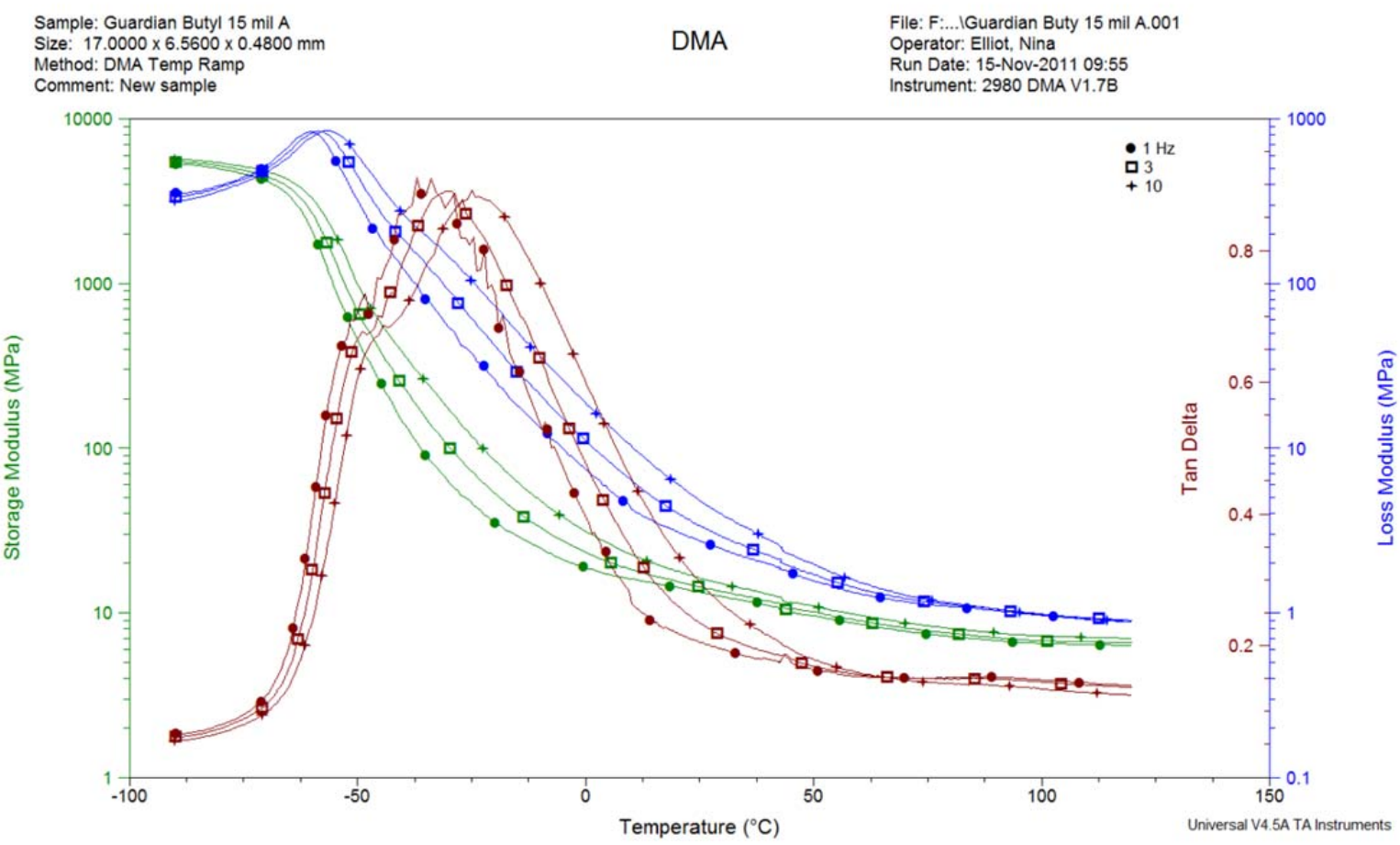

(b) Log

Figure 3. DMA results for a Guardian 15 mil Butyl rubber test at three loading frequencies (a) linear and (b) log plots for the Moduli.

The $T_{\mathrm{g}}$ was determined using the TA instruments data analysis software (6). A plot of the resultant analysis is shown in Figure 4. The tangent and slopes are used in the analysis program to determine the 
$T_{g}$. The average $T_{g}$ values for the butyl rubber, Viton , polyurethane, Hypalon , and polyurethaneHypalon samples are listed in Table 2 , and the individual values are available in Appendix A. The data for the approximate $T_{g}$ for butyl rubber exhibit very little scatter and have an average of $-60.5^{\circ} \mathrm{C}$ and a standard deviation of $0.71^{\circ} \mathrm{C}$. The other gloves have significantly higher $\mathrm{T}_{\mathrm{g}} \mathrm{s}$ at $-30^{\circ} \mathrm{C}$ for polyurethane and approximately $-16^{\circ} \mathrm{C}$ for Hypalon ${ }^{\circ}$ and Viton ${ }^{\circ}$. The composite glove of polyurethane-Hypalon has a $\mathrm{T}_{\mathrm{g}}$ that is intermediate between polyurethane and Hypalon ${ }^{\circ}$, as shown in Figure 5; the other composite gloves ( $\mathrm{BV}$ and $\mathrm{BH}$ ) exhibited unexpected behavior and will be discussed subsequently. The individual plots for the $1 \mathrm{~Hz}$ data for all of the samples are presented in Appendix B.

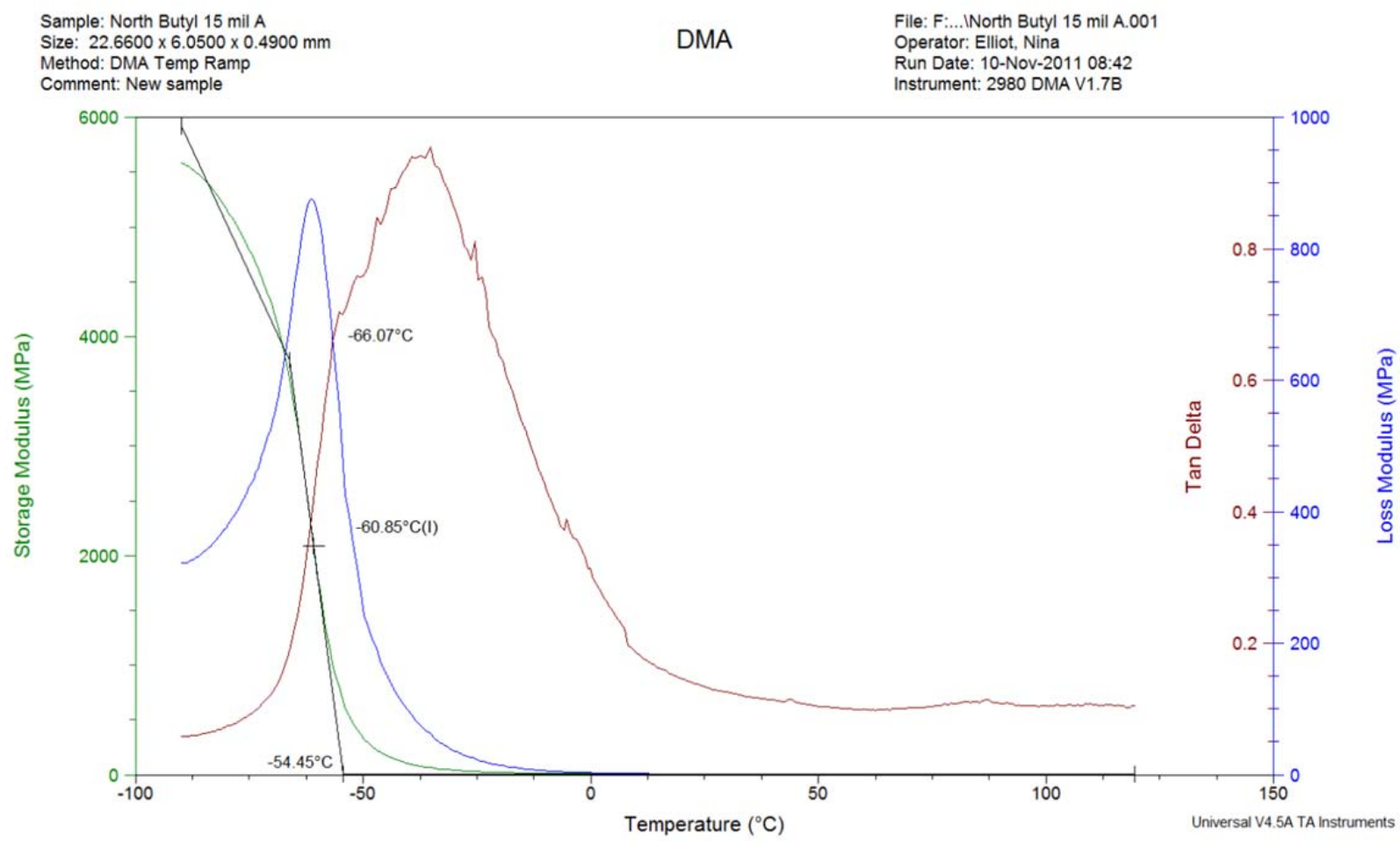

Figure 4. Determination of $\operatorname{Tg}(-60.07)$ for the North Butyl at $1 \mathrm{~Hz}$.

Examination of the DMA data plots over the entire temperature range tested may indicate physical and structural property changes. For instance, there is an unexpected change in the $\tan \delta$ of the North butyl rubber between 50 and $75^{\circ} \mathrm{C}$, Figure 4 . The storage modulus decreases with increasing temperature across the entire test range; however, the loss modulus and consequently, the $\tan \delta$ values exhibit an increase, as shown in Figure 6. This deviation from the expected continuous reduction in loss modulus with increasing temperature coincides with an observed discontinuity of the permeability of butyl rubber (3) over the range of 25 to $75^{\circ} \mathrm{C}$. Thus, the non-Arrhenius relationship of permeation rate with temperature appears to be related to a real structural change in the polymer. The change in physical or structural properties measured across the potential use temperature suggests that additional testing may be warranted to better characterize the temperature effects on permeability and structure/properties. 
Table 2. Average measured $\mathrm{Tg}$, Storage Modulus, and Tan $\delta$ for all the samples.

\begin{tabular}{|l|r|r|r|r|}
\hline & $\begin{array}{l}\sim \text { Approx } \\
\mathrm{T}_{\mathrm{g}}\left({ }^{\circ} \mathrm{C}\right)\end{array}$ & $\begin{array}{l}\text { Actual } \\
\mathrm{T}_{\mathrm{g}}\left({ }^{\circ} \mathrm{C}\right)\end{array}$ & $\begin{array}{l}\text { Storage } \\
\text { Modulus at } \\
\mathrm{T}_{\mathrm{g}} \text { (Mpa) }\end{array}$ & $\begin{array}{l}\text { Tan } \delta \\
\text { at } \mathrm{T}_{\mathrm{g}}\end{array}$ \\
\hline $\mathrm{G} 15$ & -60.8 & -68.6 & 4201 & 0.137 \\
\hline G30 & -60.6 & -68.7 & 4397 & 0.133 \\
\hline N15 & -60.7 & -68.4 & 3795 & 0.140 \\
\hline N30 & -60.2 & -68.1 & 4306 & 0.130 \\
\hline P15 & -60.6 & -68.4 & 2794 & 0.137 \\
\hline P30 & -60.4 & -68.7 & 4288 & 0.132 \\
\hline P15ESDB & -60.6 & -68.4 & 3739 & 0.136 \\
\hline P24ESDB & -59.6 & -69.4 & 3566 & 0.136 \\
\hline P25Y & -16.2 & -25.1 & 1489 & 0.067 \\
\hline P15U & -30.6 & -39.2 & 1852 & 0.068 \\
\hline P20UY & -24.1 & -35.3 & 1935 & 0.055 \\
\hline J24V & -17.0 & -24.5 & 2738 & 0.089 \\
\hline J31V & -16.5 & -24.4 & 2749 & 0.100 \\
\hline
\end{tabular}

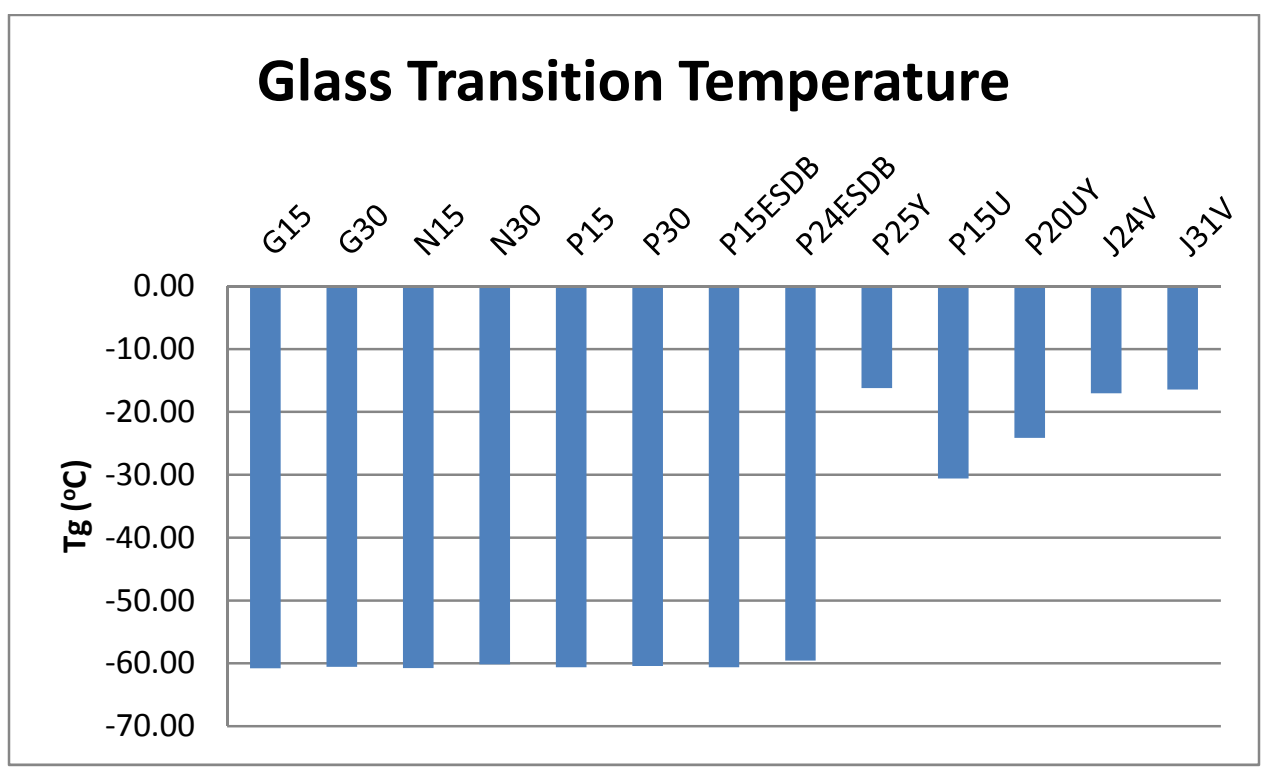

Figure 5. Graphical representation of the glass transition temperature gloves with single $\mathrm{T}_{\mathrm{g}}$. 
Sample: North Butyl 30 mil C

DMA File: F:IDMAINorth Butyl 30 mil C.001

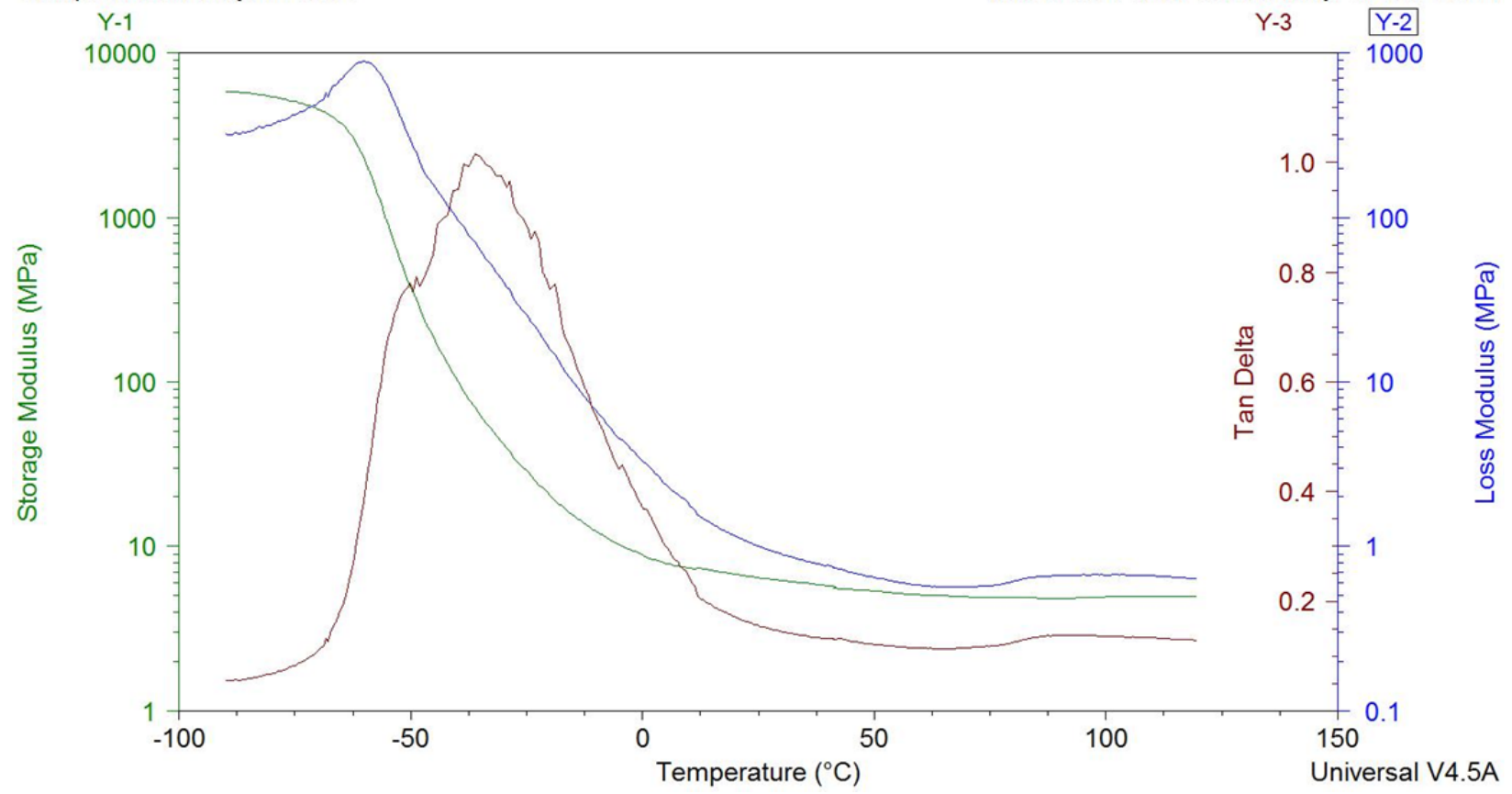

Figure 6. North 30 mil Butyl exhibiting an increase in the loss modulus between 50 and $75^{\circ} \mathrm{C}$.

Jung Butyl-Hypalon (JBH) and Jung Butyl-Viton (JBV) gloves were also evaluated using DMA. These materials exhibited more complex behaviors and have more than on glass transition temperature. The DMA results for Butyl-Hypalon are shown in Figure 7, and those of Butyl-Viton in Figure 8. The plots are far more complex than the previous test results. The JBH27.5 exhibits multiple transitions at about $60,-20$, and $2^{\circ} \mathrm{C}$. The first two $\mathrm{T}_{\mathrm{g}}$ values are consistent with the base polymers of this composite and the third is not. Additional testing to determine the cause would be required. The JBV20 sample exhibits dual $\mathrm{T}_{\mathrm{g}} \mathrm{s}$, one at -60 and one at $-9^{\circ} \mathrm{C}$. The $-60^{\circ} \mathrm{C}$ is consistent with butyl while the $-9^{\circ} \mathrm{C}$ is close to that observed for $\operatorname{Viton}^{\circledR}$, i.e., $-16^{\circ} \mathrm{C}$. No intermediate $T_{\mathrm{g}}$ was detected suggesting that there is no interaction between the butyl and Viton ${ }^{\circledR}$, while there may be an interaction between butyl and Hypalon ${ }^{\circledR}$. 


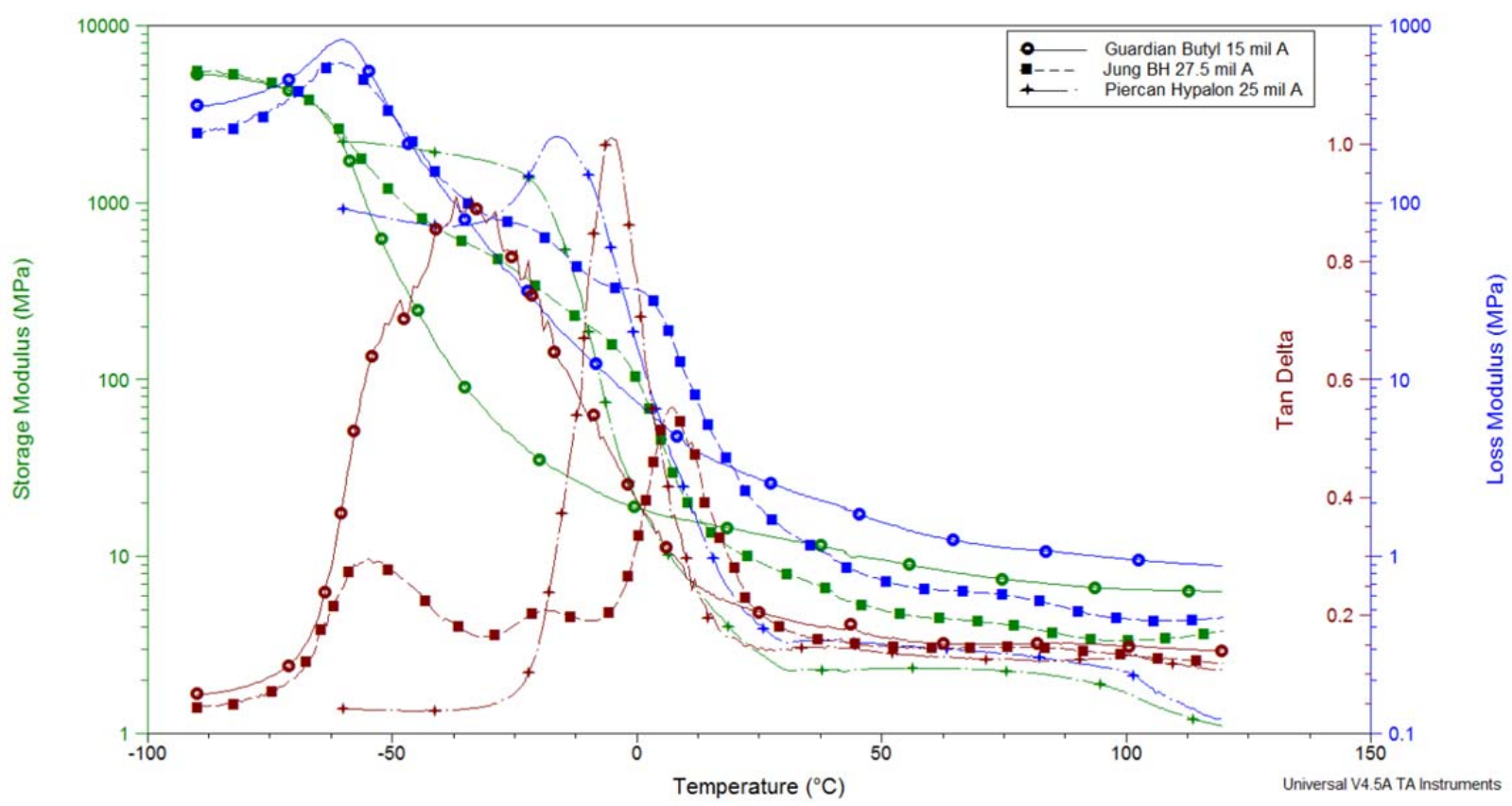

Figure 7. DMA results for Jung Butyl-Hypalon with both Butyl and Hypalon overlays.

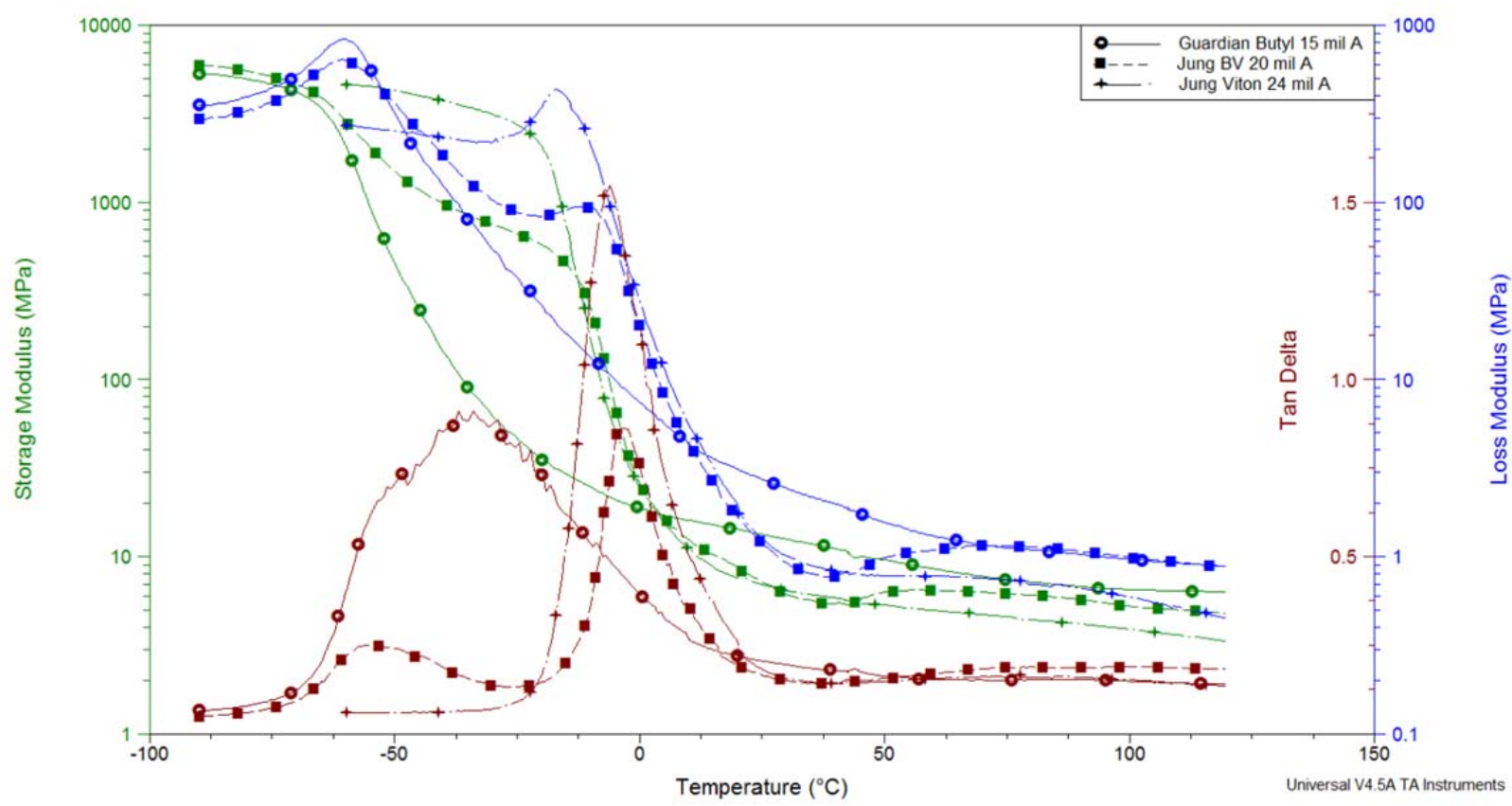

Figure 8. DMA results for Jung Butyl-Viton with both Butyl and Viton overlays.

\section{Summary and Conclusions}

The glass transition temperature, $T_{g}$, of the materials used in gloves of interest for SRS Tritium Facility glovebox use was determined. The $\mathrm{T}_{\mathrm{g}}$ of all the butyl gloves was consistent and about $-60^{\circ} \mathrm{C}$. The composite gloves exhibited three different behaviors: the Polyurethane-Hypalon ${ }^{\circledR}$ had a $\mathrm{T}_{\mathrm{g}}$ that was intermediate between Polyurethane and Hypalon ${ }^{\circledR}$; the butyl-Viton glove exhibited two distinct $\mathrm{T}_{\mathrm{g}} \mathrm{s}$, at 
approximately the same values as the component constituents; while the butyl-Hypalon composite material exhibited three distinct $\mathrm{T}_{\mathrm{g}} \mathrm{s}$; one that was at approximately each of the constituent materials and a final one that was about $2^{\circ} \mathrm{C}$.

All of the $T_{g}$ are well below room temperature and so brittle behavior is not expected for any of the glove materials in Tritium Facility operating conditions. Even the highest measured $\mathrm{T}_{\mathrm{g}}$ of $2^{\circ} \mathrm{C}$ for the Jung butyl-Hypalon is well below room temperature.

The North butyl exhibits an increase in the loss modulus at temperatures between 50 and $75^{\circ} \mathrm{C}$. The reason for this increase was not evaluated; however, the temperature range that this deviation was observed in is consistent with the observed change in the plot of log permeation rate as a function of reciprocal temperature.

\section{Acknowledgements}

The authors would like to thank Tritium Operations, Tritium Engineering, and Tritium Extraction Facility for technical and financial support.

\section{References}

1. SRNL-STI-2012-00030, Thermogravimetric Characterization of Glovebox Gloves, P.S. Korinko, Y. Breakiron, Feb 29, 2012

2. SRNL-STI-2012-00069, Characterization of Tensile Strength of Glovebox Gloves, P.S. Korinko, Y. Breakiron, G. K. Chapman, Feb 29, 2012

3. SRNL-STI-2012-00028, Evaluation of Glovebox Gloves for Effective Permeation Control, P.S. Korinko, Y. Breakiron, Feb 29, 2012

4. SRNL-STI-2012-00068, Puncture Test Characterization of Glovebox Gloves, P.S. Korinko, Y. Breakiron, and G.K. Chapman, Feb 29, 2012

5. Introduction to Dynamic Mechanical Analysis (DMA), (2008 PerkinElmer, Inc.

6. TA Instruments Universal Analysis 2000, V 4.5A, (C) 1998-2007, TA Instruments-Waters, LLC. 
Appendix A:

\begin{tabular}{|c|c|c|c|c|c|c|c|c|c|c|c|c|}
\hline & $\begin{array}{c}\text { Approx } \\
\text { imated } \\
\operatorname{Tg}\left({ }^{\circ} \mathrm{C}\right)\end{array}$ & $\begin{array}{l}\text { Actual } \\
\mathrm{Tg} \\
\left({ }^{\circ} \mathrm{C}\right)\end{array}$ & $\begin{array}{l}\text { Storage } \\
\text { Modulus } \\
\text { at Tg } \\
\text { (MPa) }\end{array}$ & $\begin{array}{l}\operatorname{Tan} \delta \\
\text { at } \operatorname{Tg}\end{array}$ & $\begin{array}{c}\text { Storage } \\
\text { Modulus } \\
\text { at } 22^{\circ} \mathrm{C} \\
(\mathrm{MPa})\end{array}$ & $\begin{array}{c}\text { Storage } \\
\text { Modulus } \\
\text { at } 50^{\circ} \mathrm{C} \\
(\mathrm{MPa})\end{array}$ & $\begin{array}{c}\text { Storage } \\
\text { Modulus } \\
\text { at } 75^{\circ} \mathrm{C} \\
(\mathrm{MPa})\end{array}$ & $\begin{array}{c}\text { Storage } \\
\text { Modulus } \\
\text { at } 120^{\circ} \mathrm{C} \\
(\mathrm{MPa})\end{array}$ & $\begin{array}{l}\operatorname{Tan} \delta \\
\text { at } 22^{\circ}\end{array}$ & $\begin{array}{l}\operatorname{Tan} \delta \\
\text { at } 50^{\circ}\end{array}$ & $\begin{array}{l}\operatorname{Tan} \delta \\
\text { at } 90^{\circ}\end{array}$ & $\begin{array}{l}\operatorname{Tan} \delta \\
\text { at } 120^{\circ}\end{array}$ \\
\hline G15BA & -60.5 & -68.4 & 3993 & 0.141 & 13.87 & 9.59 & 6.77 & 6.33 & 0.213 & 0.162 & 0.152 & 0.140 \\
\hline G15BB & -61.1 & -68.8 & 4409 & 0.133 & 15.15 & 10.67 & 7.59 & 7.11 & 0.210 & 0.162 & 0.153 & 0.141 \\
\hline G30BA & -60.9 & -68.6 & 4527 & 0.137 & 15.16 & 10.65 & 7.62 & 6.93 & 0.191 & 0.154 & 0.144 & 0.131 \\
\hline G30BB & -60.3 & -68.8 & 4266 & 0.130 & 14.93 & 10.78 & 8.04 & 7.65 & 0.216 & 0.177 & 0.179 & 0.169 \\
\hline N15BA & -61.3 & -68.8 & 4095 & 0.140 & 8.70 & 6.26 & 1.73 & 1.64 & 0.141 & 0.104 & 0.109 & 0.105 \\
\hline N15BB & -60.2 & -68.1 & 3495 & 0.141 & 9.54 & 8.34 & 6.50 & 5.29 & 0.170 & 0.127 & 0.150 & 0.143 \\
\hline N30BA & NA & NA & $\mathrm{NA}$ & NA & NA & 6.55 & 5.78 & 5.45 & NA & 0.120 & 0.168 & 0.156 \\
\hline N30BB & NA & NA & NA & NA & 6.88 & 6.01 & 5.10 & 4.60 & 0.207 & 0.157 & 0.190 & 0.167 \\
\hline N30BC & -60.2 & -68.1 & 4306 & 0.130 & 6.63 & 5.35 & 4.82 & 4.97 & 0.164 & 0.121 & 0.138 & 0.129 \\
\hline P15BA & -60.0 & -68.2 & 2779 & 0.137 & 1.91 & 1.16 & 0.48 & NA & 0.149 & 0.098 & 0.089 & NA \\
\hline P15BB & -60.4 & -68.3 & 2695 & 0.137 & 0.90 & 0.52 & 0.50 & NA & 0.141 & 0.094 & 0.082 & NA \\
\hline P15BC & -61.5 & -68.7 & 2907 & 0.136 & 1.24 & 1.07 & 0.70 & 0.73 & 0.157 & 0.121 & 0.116 & 0.063 \\
\hline P30BA & -60.0 & -68.6 & 4395 & 0.136 & 13.31 & 9.64 & 7.10 & 6.71 & 0.200 & 0.157 & 0.141 & 0.128 \\
\hline P30BB & -60.8 & -68.8 & 4180 & 0.129 & 11.32 & 8.15 & 6.03 & 5.50 & 0.213 & 0.165 & 0.147 & 0.130 \\
\hline P15ESDBA & -60.6 & -68.3 & 3913 & 0.141 & 7.33 & 5.04 & 2.77 & 2.71 & 0.189 & 0.151 & 0.154 & 0.138 \\
\hline P15ESDBB & -60.6 & -68.6 & 3565 & 0.131 & 5.44 & 2.87 & 1.02 & 1.02 & 0.185 & 0.141 & 0.142 & 0.181 \\
\hline P24ESDBA & -60.7 & -68.6 & 3765 & 0.135 & 7.53 & 4.66 & 2.47 & 0.68 & 0.170 & 0.138 & 0.147 & 0.134 \\
\hline P24ESDBB & -58.4 & -70.2 & 3366 & 0.136 & 7.24 & 4.97 & 2.61 & 2.26 & 0.185 & 0.147 & 0.151 & 0.136 \\
\hline P25YA & -15.9 & -24.9 & 1527 & 0.070 & 3.28 & 2.33 & 2.01 & 1.10 & 0.148 & 0.138 & 0.124 & 0.108 \\
\hline P25YB & -16.5 & -25.4 & 1450 & 0.064 & 4.93 & 1.61 & 2.07 & 1.68 & 0.158 & 0.137 & 0.113 & 0.093 \\
\hline P15UA & -30.3 & -39.4 & 1876 & 0.066 & 12.53 & 6.60 & 0.73 & NA & 0.134 & 0.091 & 0.152 & NA \\
\hline P15UB & -30.9 & -38.9 & 1827 & 0.071 & 10.20 & 3.03 & 1.06 & NA & 0.146 & 0.099 & 0.154 & NA \\
\hline P2OUYA & -26.0 & -35.8 & 1922 & 0.054 & 14.09 & 5.19 & 1.09 & NA & 0.143 & 0.120 & 0.181 & NA \\
\hline P20UYB & -22.3 & -34.8 & 1948 & 0.055 & 11.45 & 6.69 & 0.95 & NA & 0.143 & 0.124 & 0.184 & NA \\
\hline
\end{tabular}




\begin{tabular}{|c|c|c|c|c|c|c|c|c|c|c|c|c|}
\hline J24VA & -17.1 & -24.3 & 2679 & 0.094 & 7.43 & 5.33 & 4.17 & 3.34 & 0.207 & 0.147 & 0.159 & 0.135 \\
\hline J24VB & -17.0 & -24.8 & 2797 & 0.084 & 5.61 & 3.45 & 1.47 & 1.32 & 0.229 & 0.142 & 0.149 & 0.128 \\
\hline J31VA & -16.5 & -24.2 & 2544 & 0.111 & 8.83 & 6.30 & 4.24 & 3.44 & 0.207 & 0.159 & 0.180 & 0.160 \\
\hline J31VB & -16.7 & -24.8 & 2850 & 0.095 & 5.71 & 3.61 & 2.08 & 1.84 & 0.200 & 0.153 & 0.193 & 0.168 \\
\hline J31VC & -16.2 & -24.3 & 2854 & 0.094 & 9.70 & 6.89 & 4.39 & 3.56 & 0.207 & 0.160 & 0.179 & 0.158 \\
\hline
\end{tabular}

\begin{tabular}{|c|c|c|c|c|c|c|c|c|c|c|c|c|}
\hline $\begin{array}{c}\text { Sample } \\
\text { ID }\end{array}$ & $\begin{array}{l}\mathrm{T}_{\mathrm{g}} 1 \\
\left({ }^{\circ} \mathrm{C}\right)\end{array}$ & $\begin{array}{l}\mathrm{T}_{\mathrm{g}} 1 \\
\left({ }^{\circ} \mathrm{C}\right)\end{array}$ & $\begin{array}{c}\text { Storage } \\
\text { Modulus } \\
\text { at } \mathrm{T}_{\mathrm{g}} 1 \\
(\mathrm{MPa})\end{array}$ & $\begin{array}{c}\operatorname{Tan} \delta \text { at } \\
\mathrm{T}_{\mathrm{g}} 1\end{array}$ & $\begin{array}{l}\mathrm{T}_{\mathrm{g}} 2 \\
\left({ }^{\circ} \mathrm{C}\right)\end{array}$ & $\begin{array}{l}\mathrm{T}_{\mathrm{g}} 2 \\
\left({ }^{\circ} \mathrm{C}\right)\end{array}$ & $\begin{array}{c}\text { Storage } \\
\text { Modulus at } \\
\mathrm{T}_{\mathrm{g}} 2(\mathrm{MPa})\end{array}$ & $\begin{array}{l}\operatorname{Tan} \delta \\
\text { at } \mathrm{T}_{\mathrm{g}} 2\end{array}$ & $\begin{array}{l}\mathrm{Tg}_{\mathrm{g}} 3 \\
\left({ }^{\circ} \mathrm{C}\right)\end{array}$ & $\begin{array}{l}\mathrm{T}_{\mathrm{g}} 3 \\
\left({ }^{\circ} \mathrm{C}\right)\end{array}$ & $\begin{array}{l}\text { Storage } \\
\text { Modulus } \\
\text { at } \mathrm{T}_{\mathrm{g}} 3 \\
(\mathrm{MPa})\end{array}$ & $\begin{array}{l}\text { Tan } \delta \\
\text { at } T_{\mathrm{g}} 3\end{array}$ \\
\hline J275BHA & -61.4 & -69.3 & 4173 & 0.099 & -21.4 & -26.0 & 436.9 & 0.1771 & 1.8 & 1.4 & 83.4 & 0.376 \\
\hline $\mathrm{J} 275 \mathrm{BHB}$ & -60.8 & -71.1 & 4287 & 0.086 & -21.4 & -26.4 & 498.2 & 0.1671 & 2.2 & -3.0 & 154.9 & 0.231 \\
\hline J20BVA & -60.9 & -70.5 & 4705 & 0.091 & -9.0 & -13.9 & 415.7 & 0.2231 & NA & NA & NA & NA \\
\hline J20BVB & -61.4 & -71.0 & 4844 & 0.086 & -9.7 & -15.5 & 500.9 & 0.1832 & NA & NA & NA & NA \\
\hline
\end{tabular}

\begin{tabular}{|c|c|c|c|c|c|c|c|c|}
\hline & $\begin{array}{c}\text { Storage } \\
\text { Modulus } \\
\text { at } 22^{\circ} \mathrm{C} \\
(\mathrm{MPa})\end{array}$ & $\begin{array}{c}\text { Storage } \\
\text { Modulus } \\
\text { at } 50^{\circ} \mathrm{C} \\
(\mathrm{MPa})\end{array}$ & $\begin{array}{c}\text { Storage } \\
\text { Modulus } \\
\text { at } 75^{\circ} \mathrm{C} \\
(\mathrm{MPa})\end{array}$ & $\begin{array}{c}\text { Storage } \\
\text { Modulus } \\
\text { at } 120^{\circ} \mathrm{C} \\
(\mathrm{MPa})\end{array}$ & $\begin{array}{c}\text { Tan } \delta \\
\text { at } 22\end{array}$ & $\begin{array}{c}\text { Tan } \delta \\
\text { at } 50^{\circ} \mathrm{C}\end{array}$ & $\begin{array}{c}\text { Tan } \delta \text { at } \\
90^{\circ} \mathrm{C}\end{array}$ & $\begin{array}{c}\text { Tan } \delta \text { at } \\
120^{\circ} \mathrm{C}\end{array}$ \\
\hline J275BHA & 10.17 & 4.97 & 3.49 & 3.80 & 0.236 & 0.148 & 0.141 & 0.119 \\
\hline J275BHB & 8.48 & 3.44 & 2.65 & 2.89 & 0.244 & 0.139 & 0.133 & 0.110 \\
\hline J20BVA & 8.03 & 6.32 & 5.72 & 4.76 & 0.180 & 0.156 & 0.187 & 0.184 \\
\hline J20BVB & 8.68 & 6.35 & 6.07 & 5.01 & 0.190 & 0.152 & 0.189 & 0.185 \\
\hline
\end{tabular}




\section{Appendix B:}

Sample: Jung BH 27.5 mil A

DMA File: C:...IDMAINina BreakironlJung BH 27.5 mil A.001
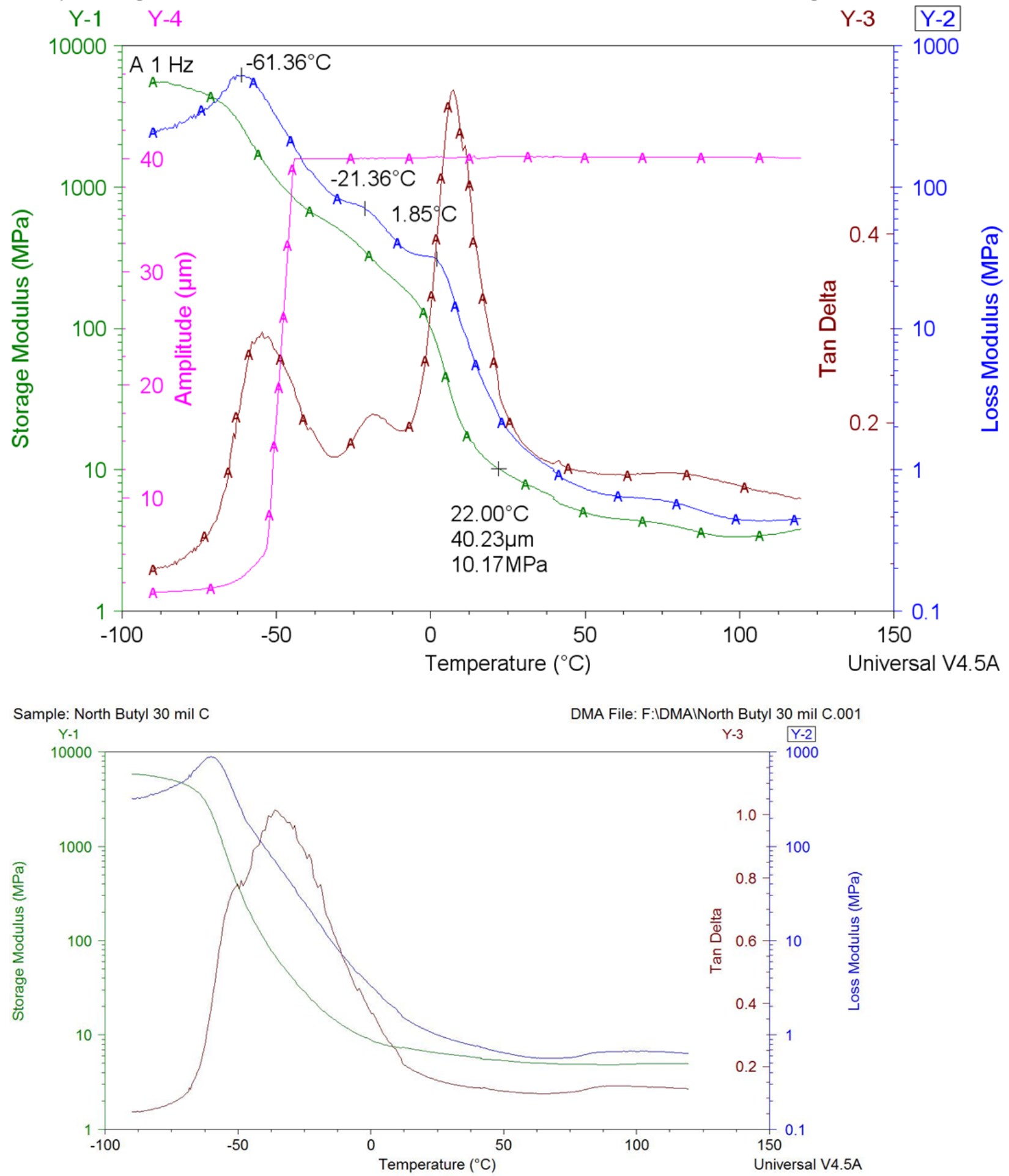
Sample: Guardian Butyl 15 mil A

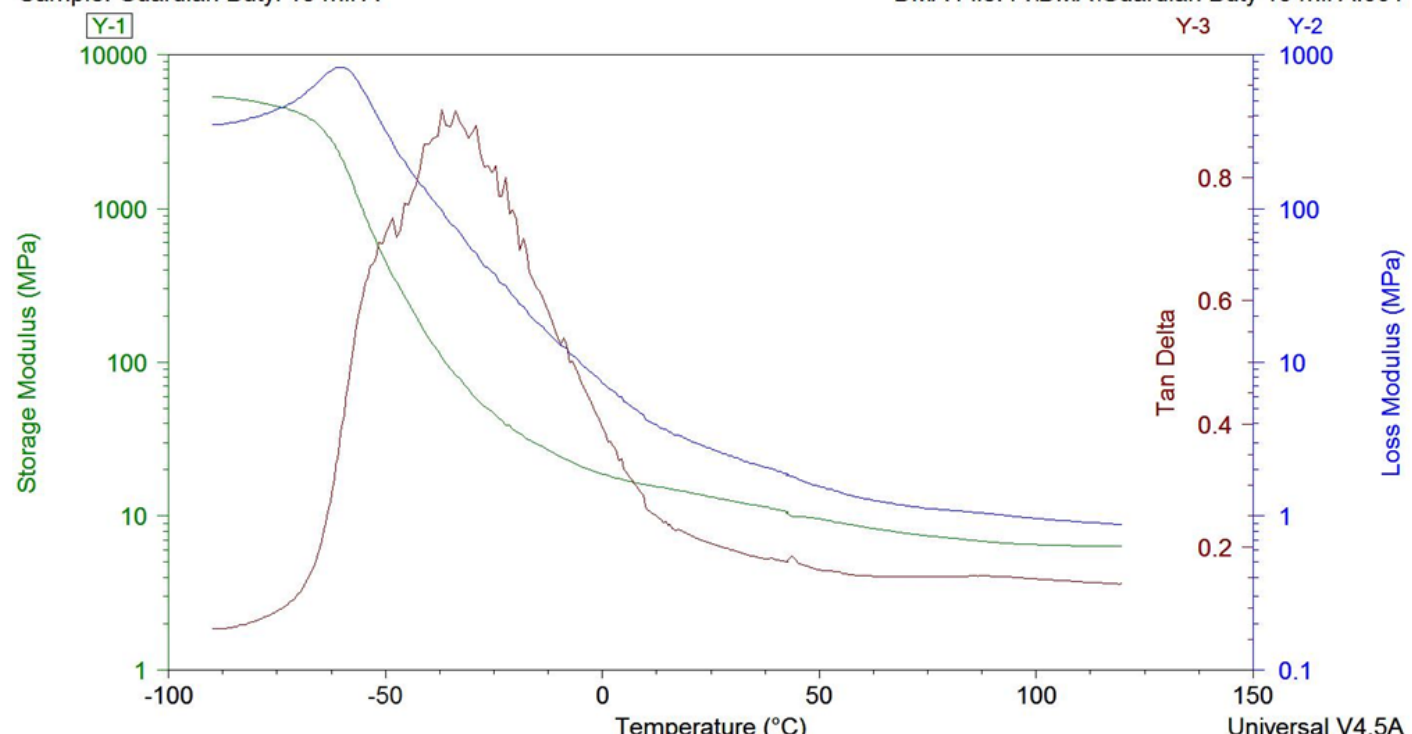

Sample: Guardian Butyl 15 mil B

$Y-1$

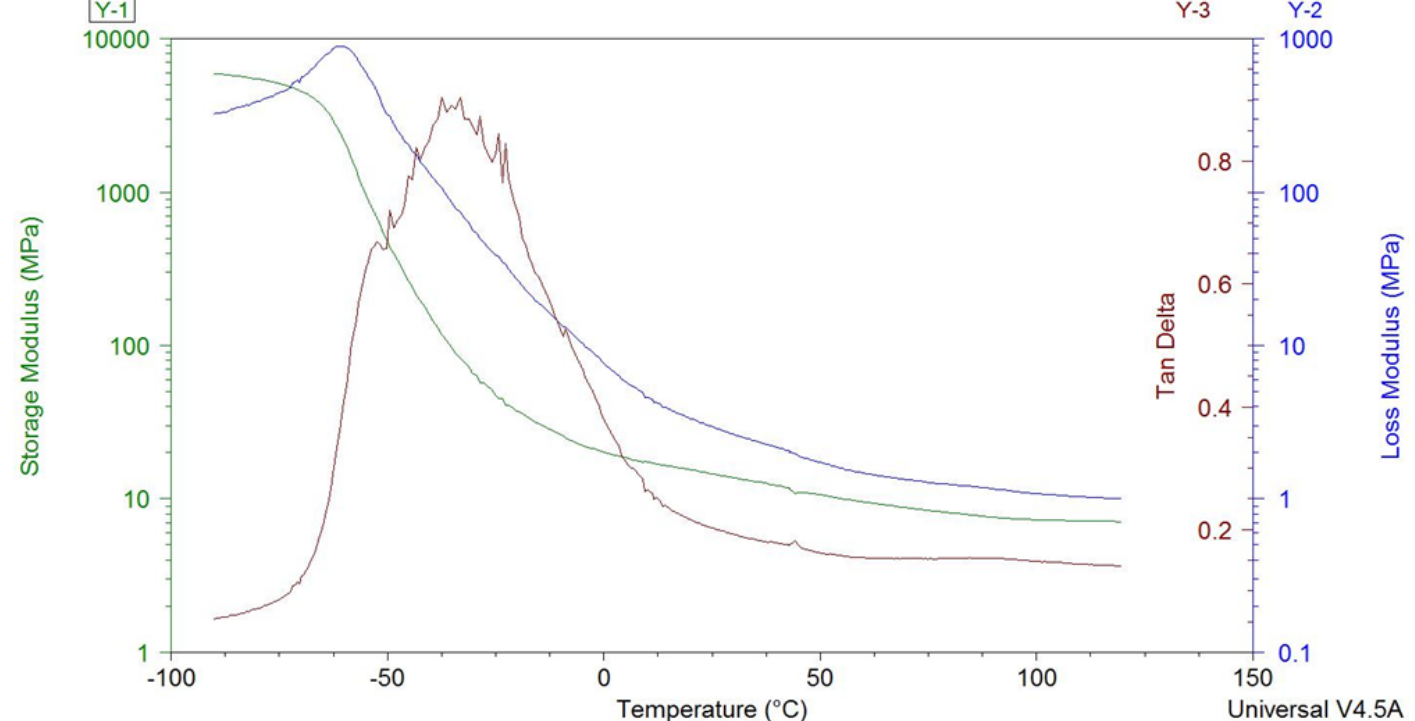

Sample: Guardian Butyl 30 mil A

$\mathrm{Y}-1$

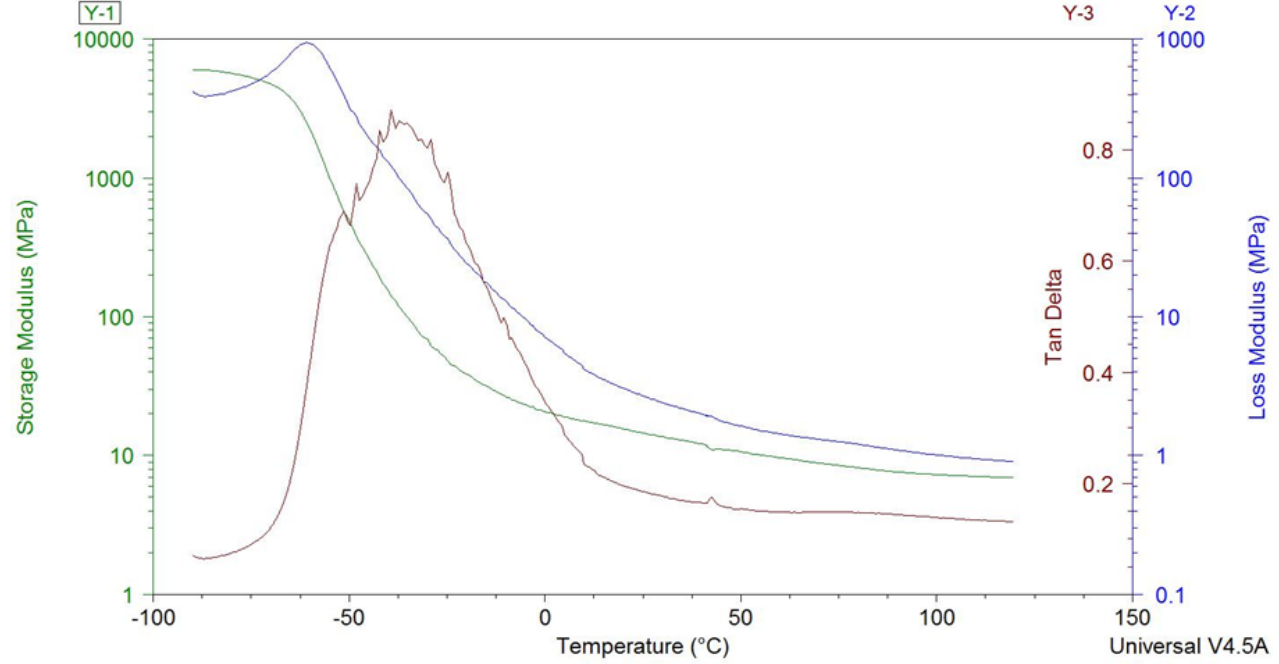


Sample: Guardian Butyl 30 mil B

DMA File: F:IDMAIGuardian Butyl 30 mil B.001

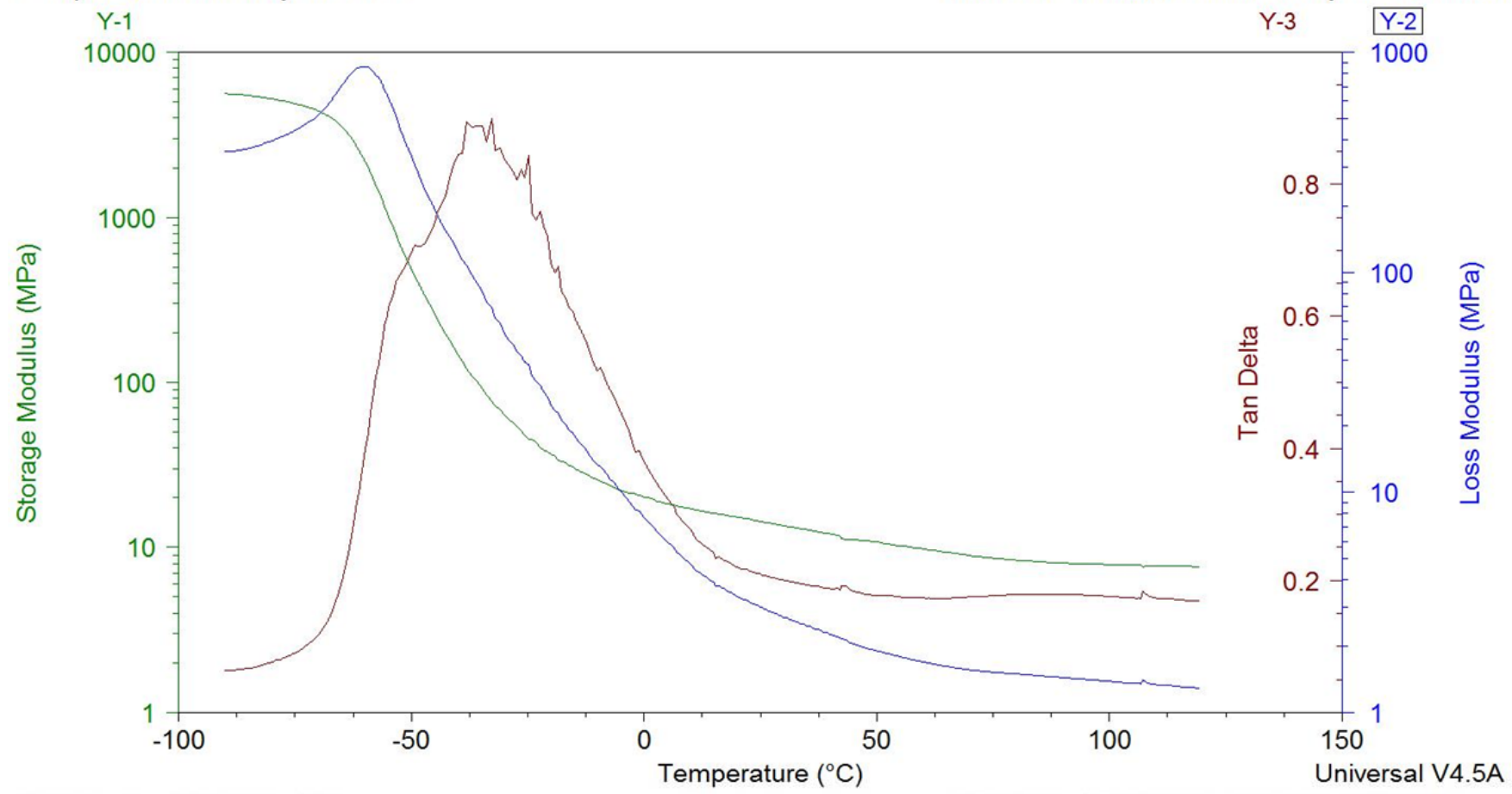

Sample: Jung BH 27.5 mil A

DMA File: F:IDMAIJung BH 27.5 mil A.001

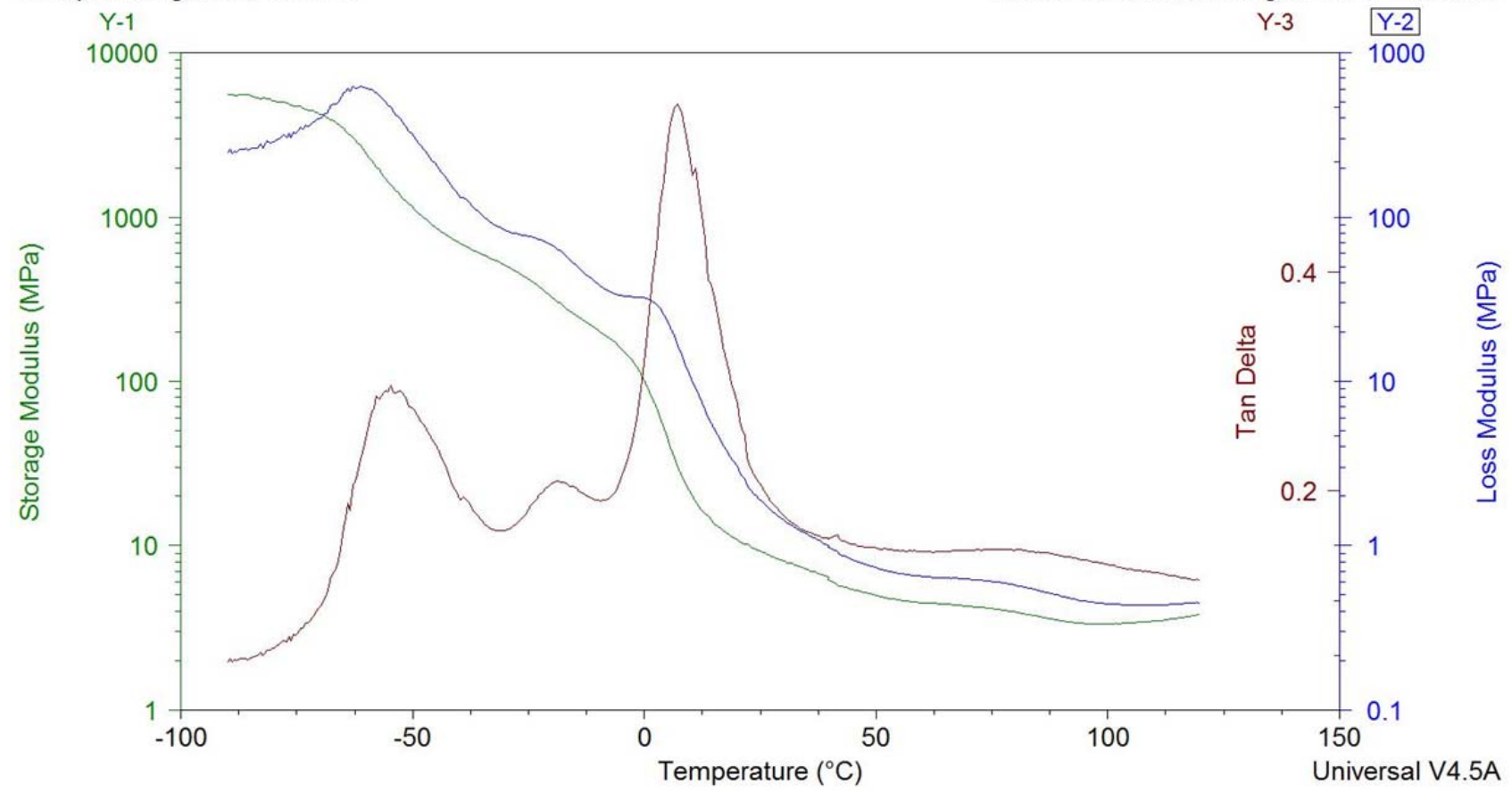


Sample: Jung BH 27.5 mil B

DMA File: F:IDMAIJung BH 27.5 mil B.001

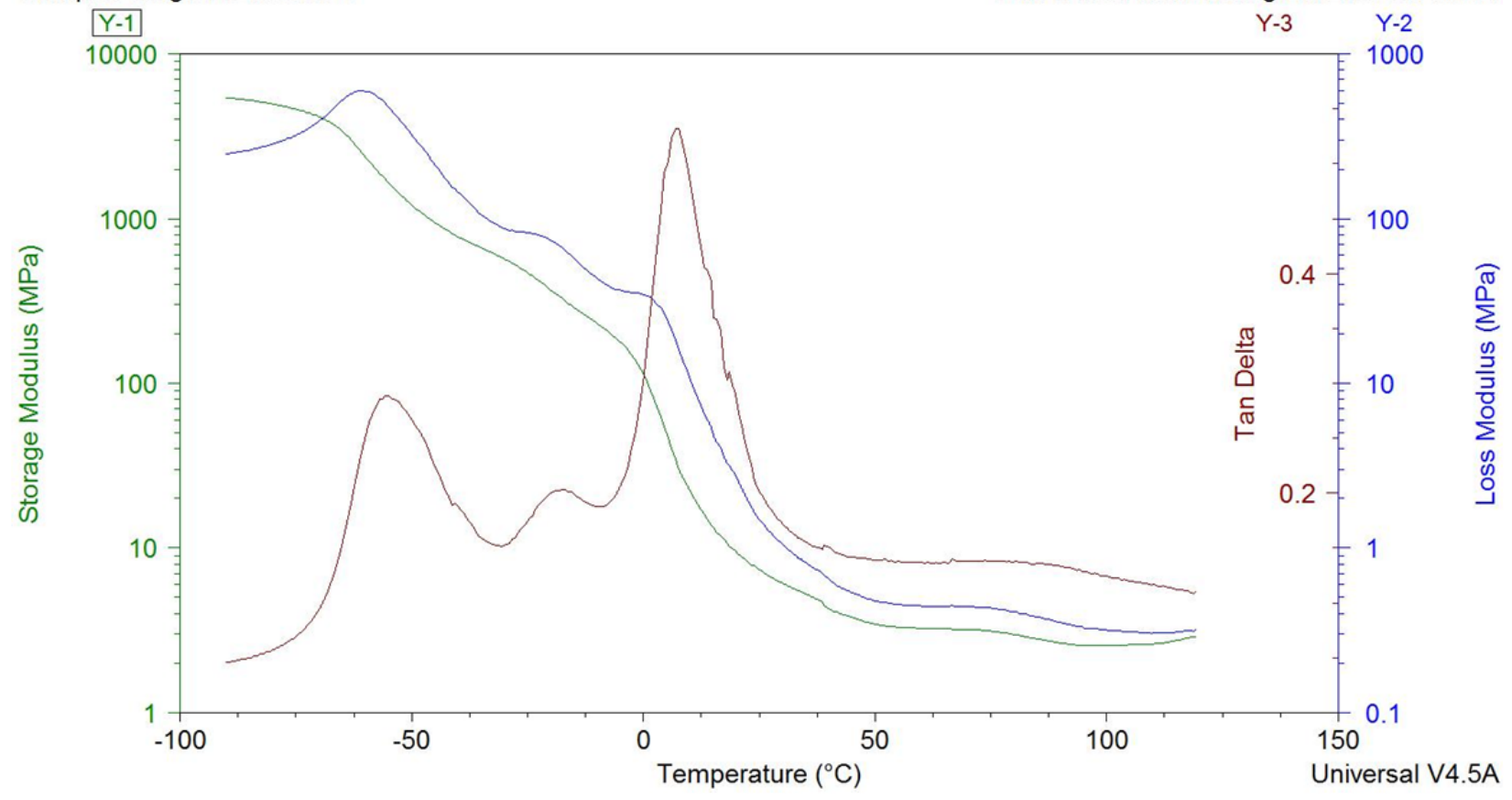

Sample: Jung BH 27.5 mil A

DMA File: C....IDMAINina Breakiron Jung BH 27.5 mil A.001

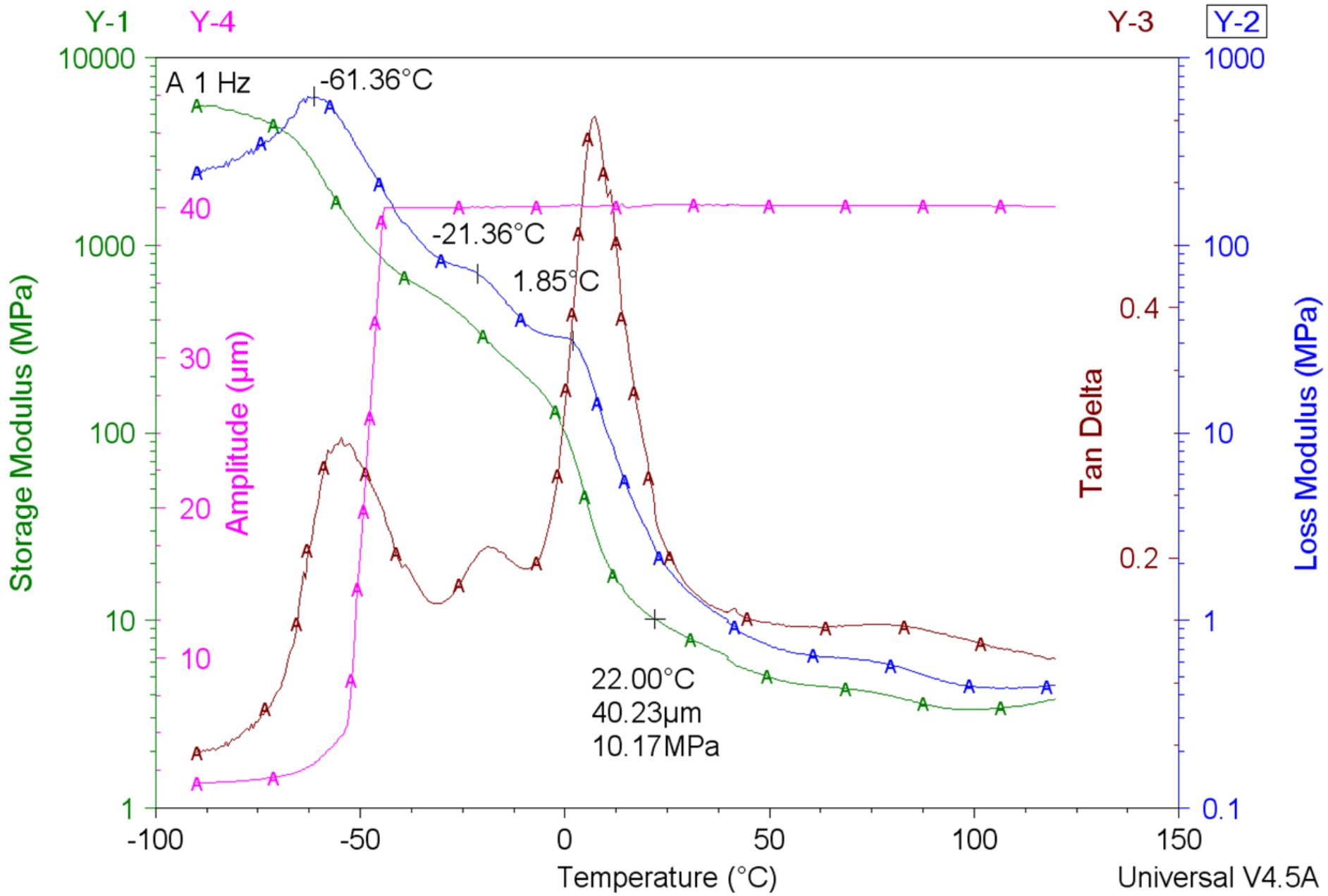


Sample: Jung BV 20 mil A

DMA File: F:IDMAlJung BV 20 mil A.001

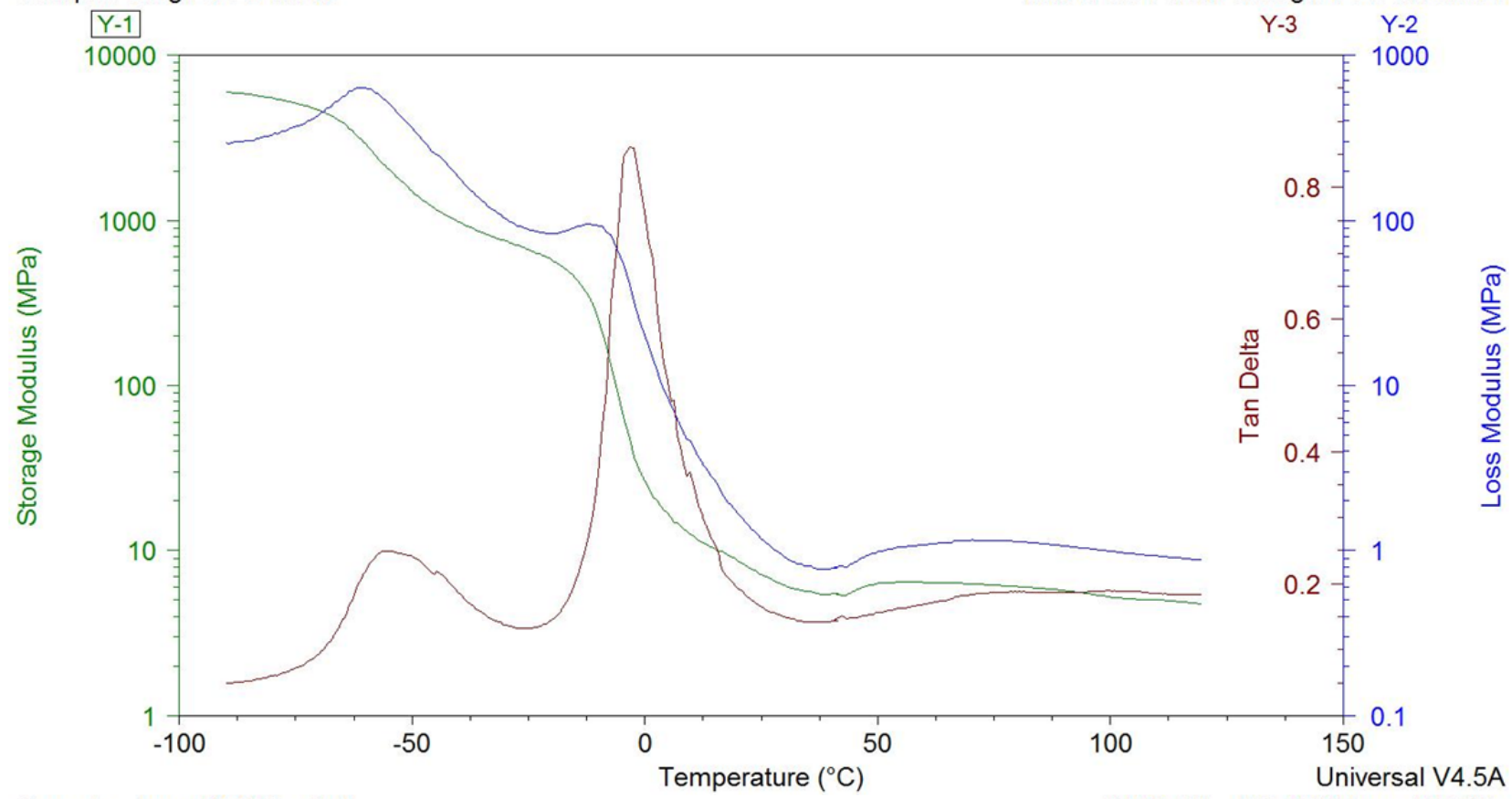

Sample: Jung BV 20 mil B

DMA File: F:IDMAlJung BV 20 mil B.001

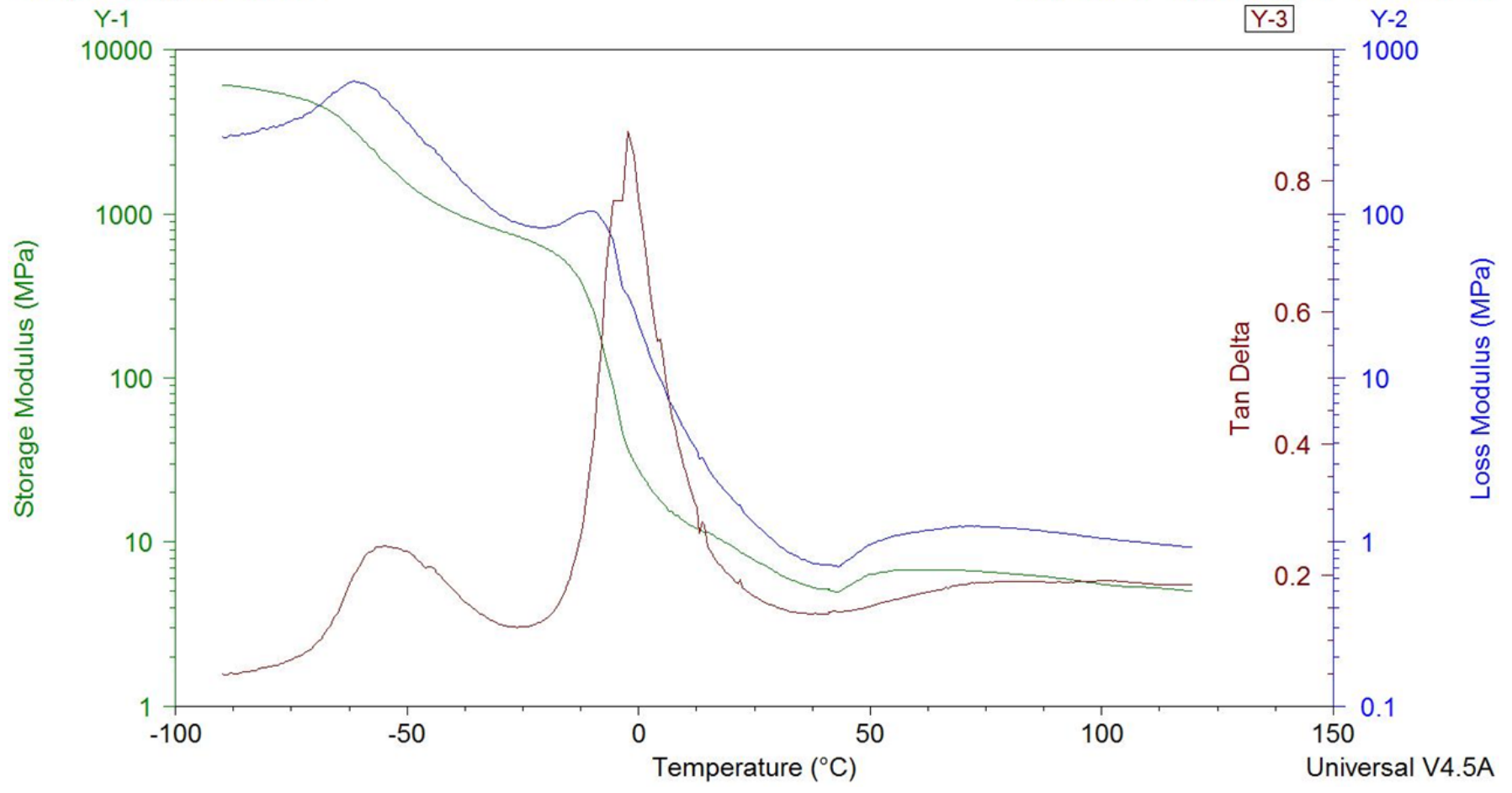


Curve 1: Jung BV 20 mil A

DMA File: C:ITAIDatalDMAINina BreakironlJung BV 20 mil A.001

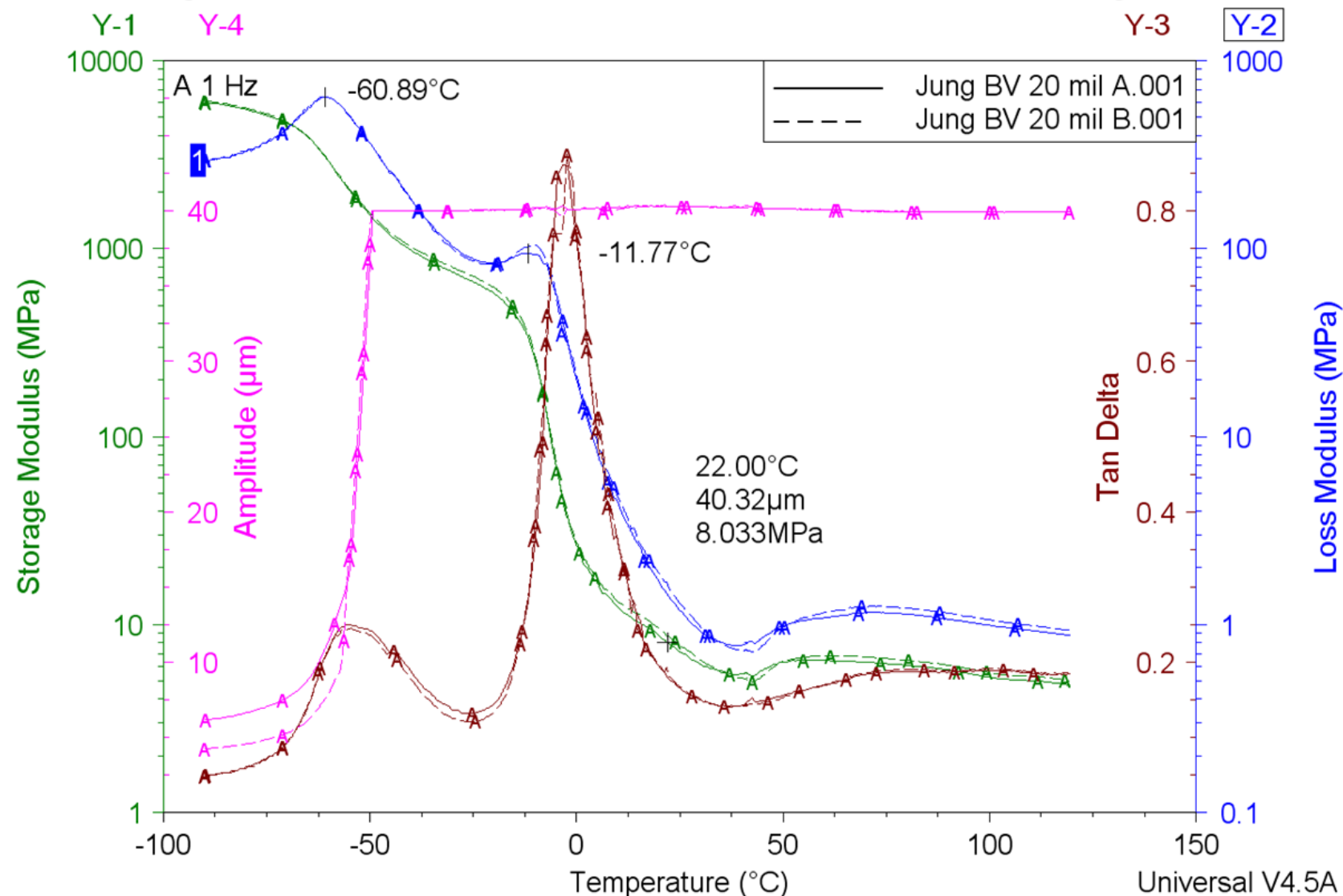

Sample: Jung Viton 24 mil A

DMA File: F:IDMAIJung Viton 24 mil A.001

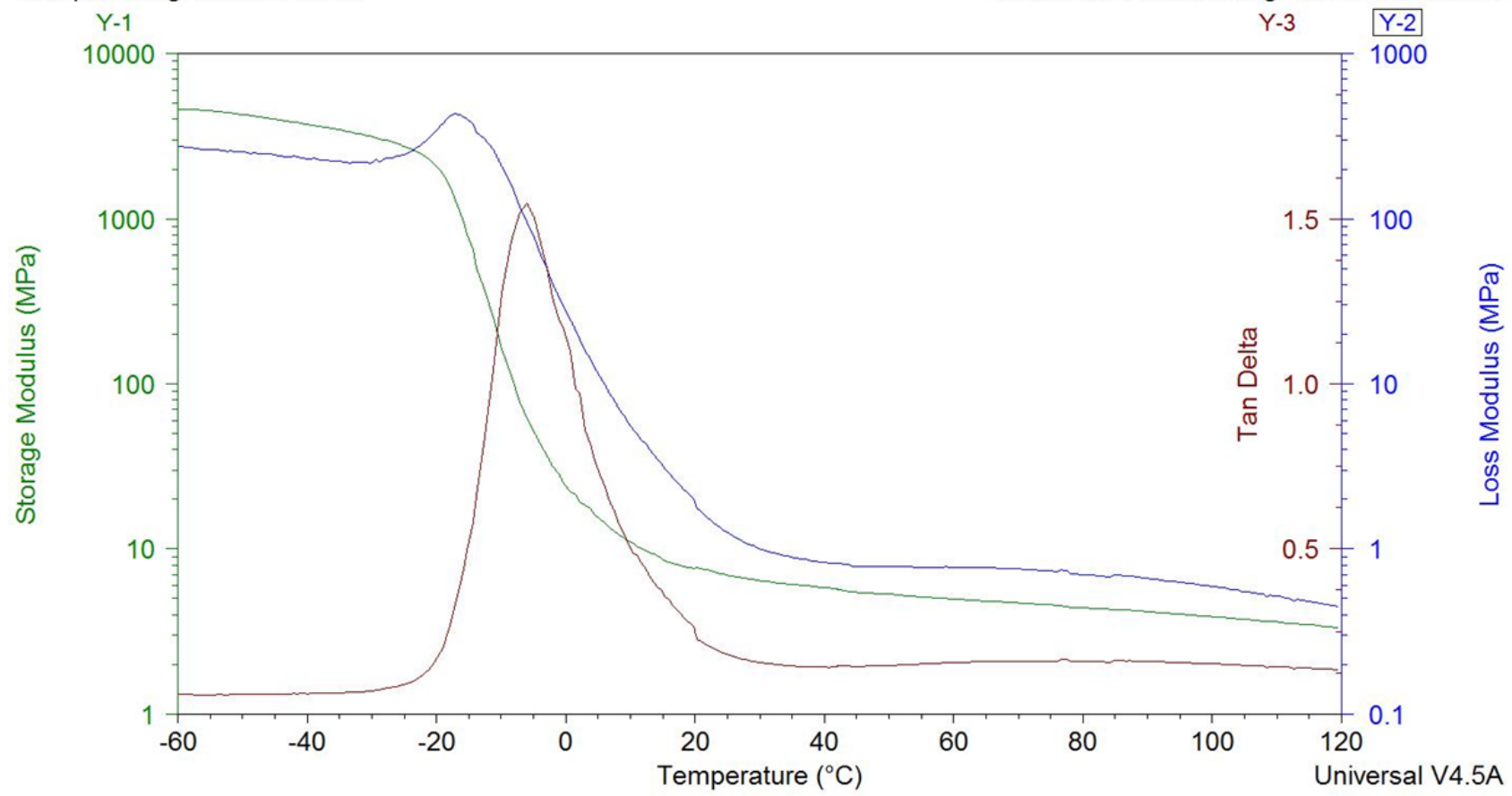


Sample: Jung Viton 24 mil B

DMA File: C.....IDMAINina BreakironIJung Viton 24 mil B.001

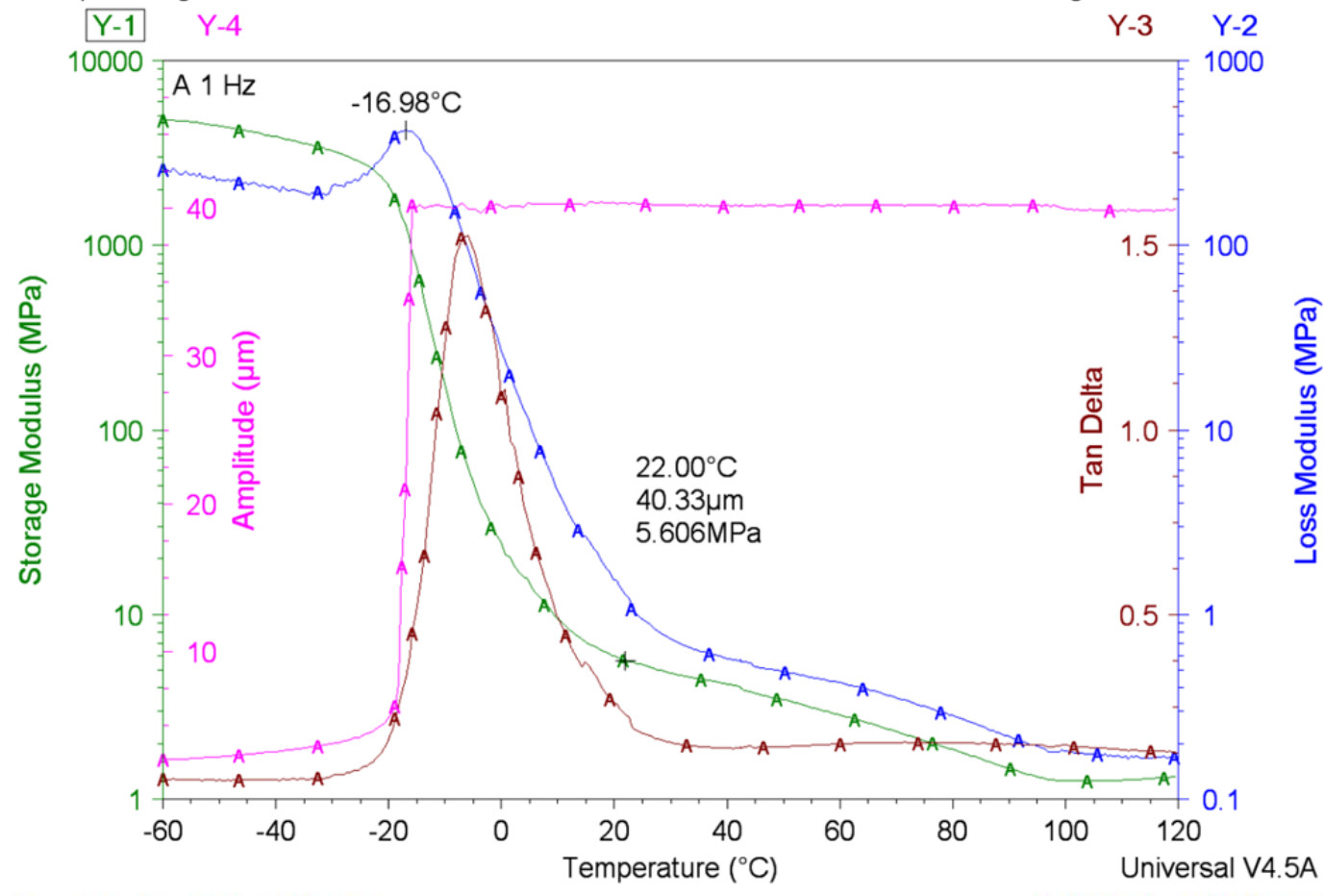

Sample: Jung Viton 24 mil B

DMA File: F:IDMAlJung Viton 24 mil B.001

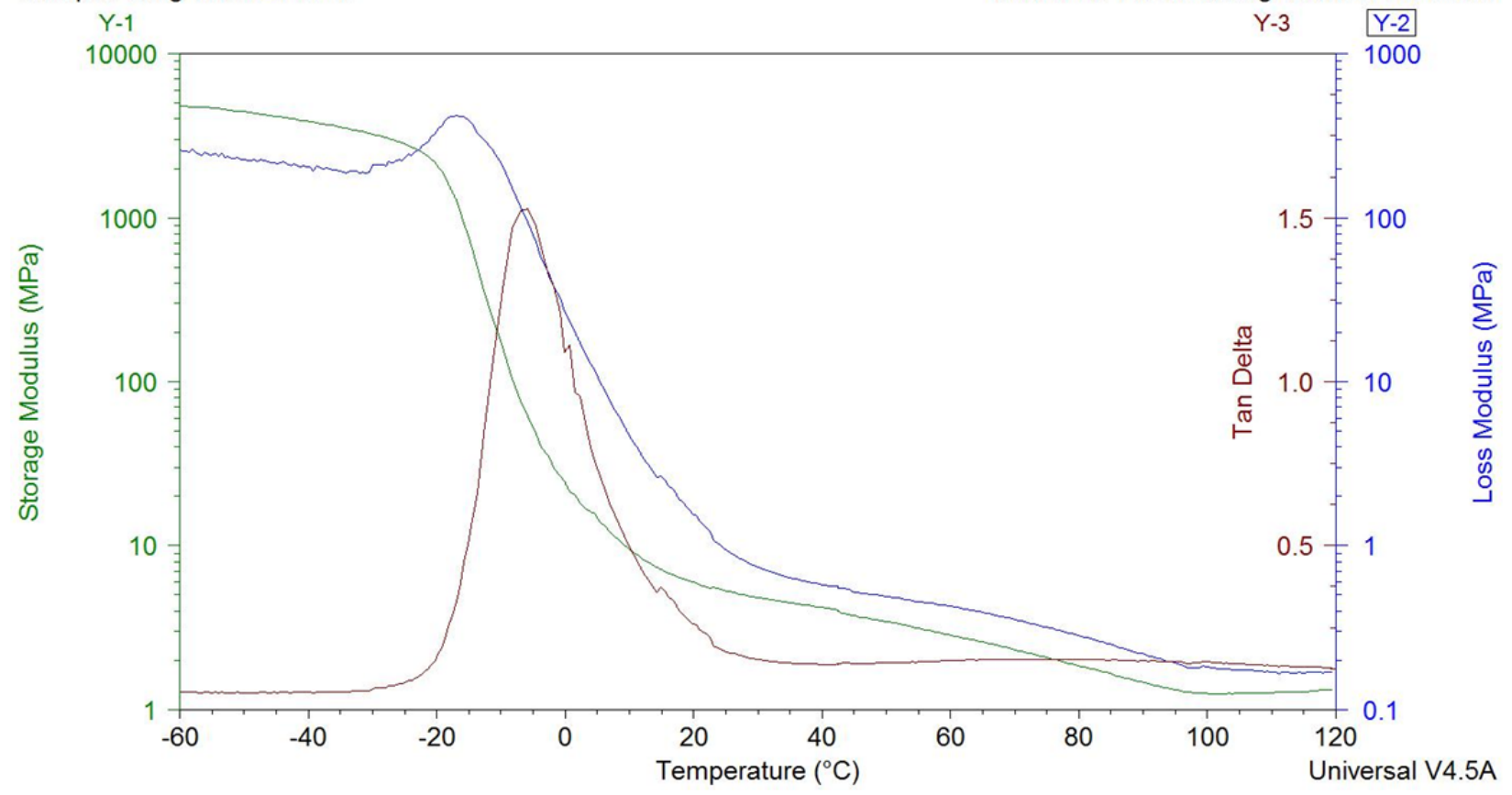


Sample: Jung Viton 31 mil A

$\mathrm{Y}-1$

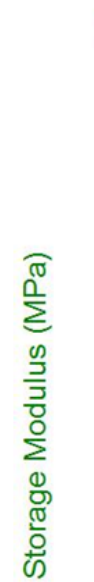$$
10000
$$

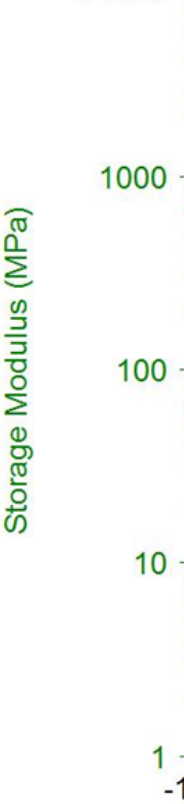

DMA File: F:IDMAIJung Viton 31 mil A.001

Y-2

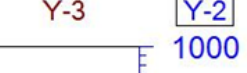

Sample: Jung Viton 31 mil B $Y-1$

DMA File: F:IDMAlJung Vito
\[ \mathrm{Y}-3 \]

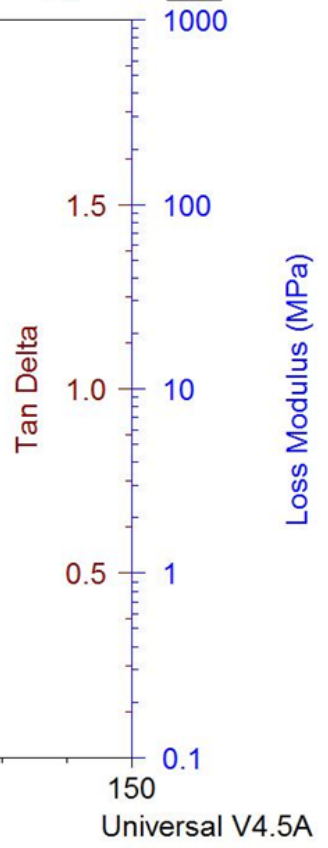


Sample: Jung Viton 31 mil C

DMA File: F:IDMAlJung Viton 31 mil C.001

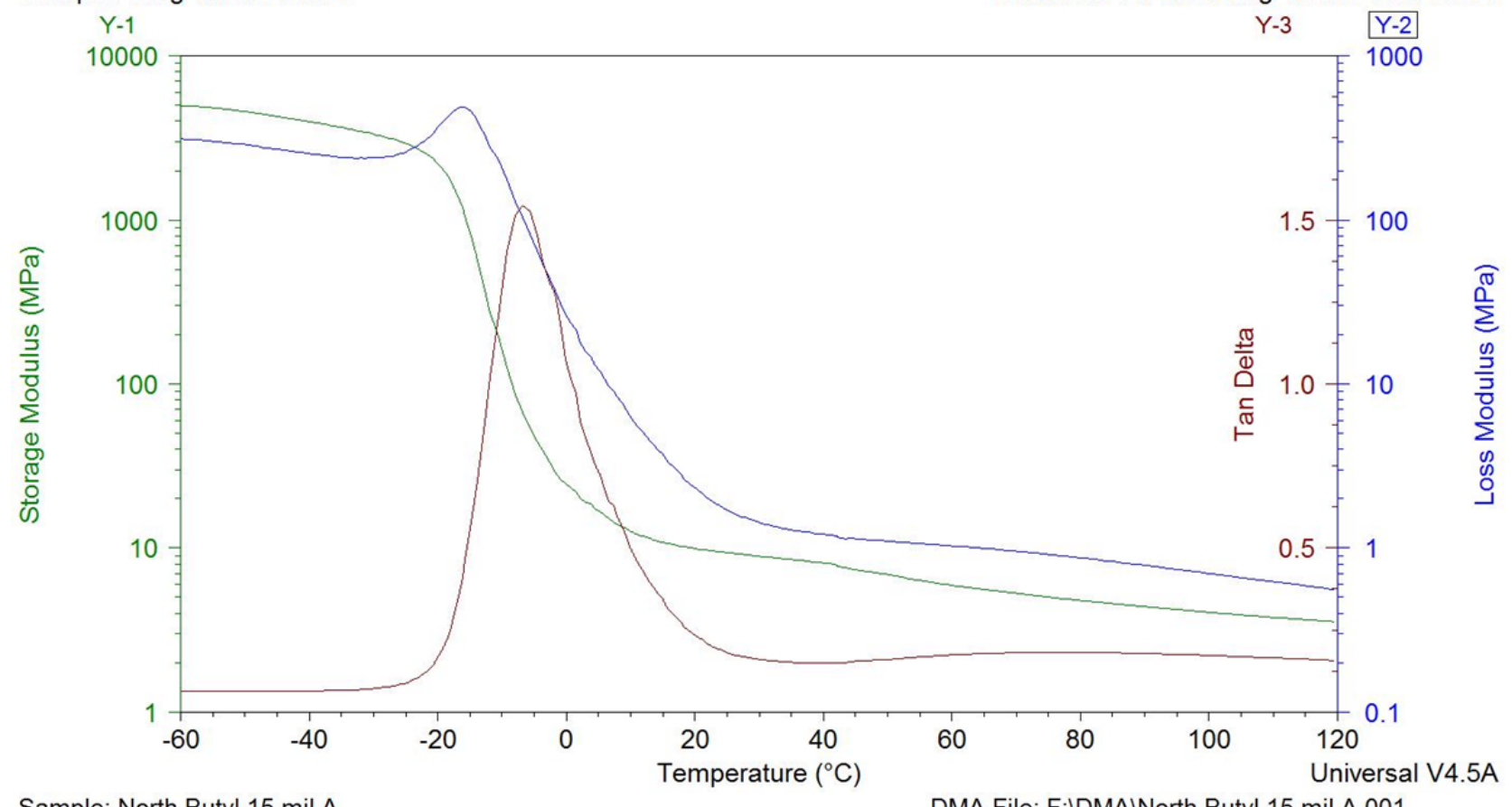

Sample: North Butyl 15 mil A

DMA File: F:IDMAINorth Butyl 15 mil A.001

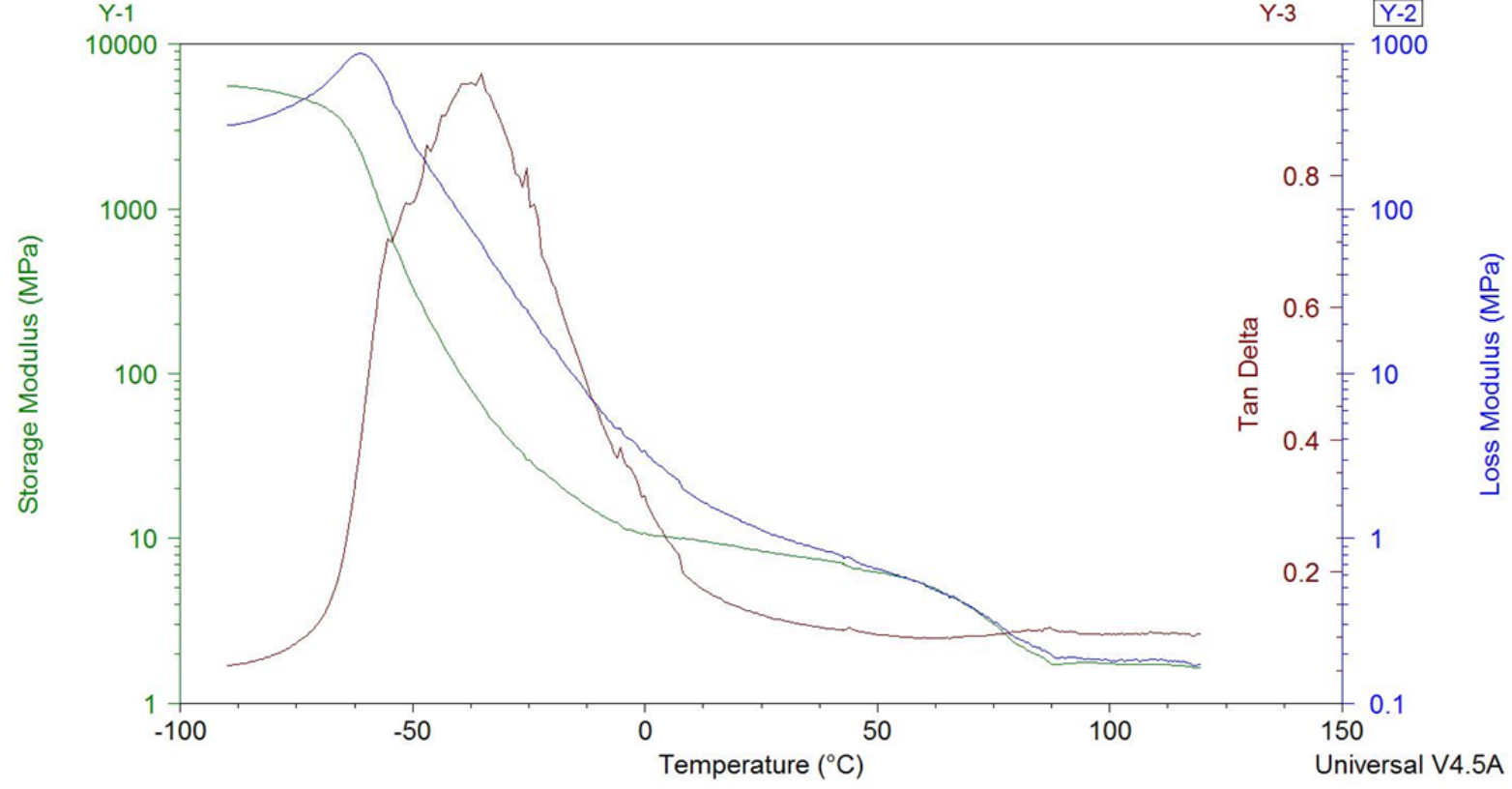


Sample: North Butyl 15 mil B

$\mathrm{Y}-1$

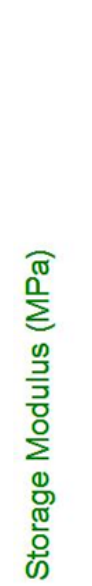

10000

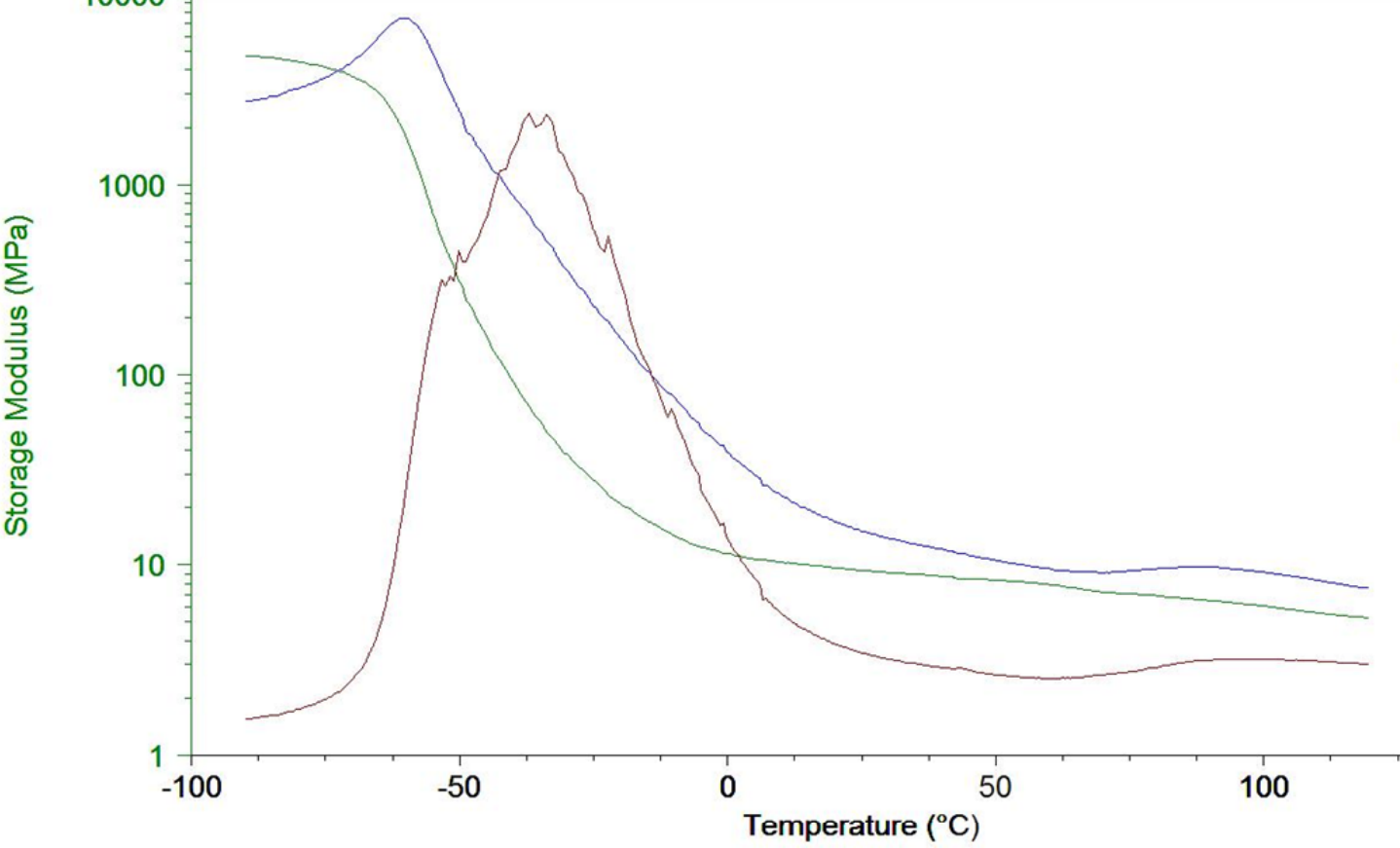

DMA File: F:IDMAINorth Butyl 15 mil B.001

$\mathrm{Y}-3 \quad \mathrm{Y}-2$

$=1000$

1.0

E 100

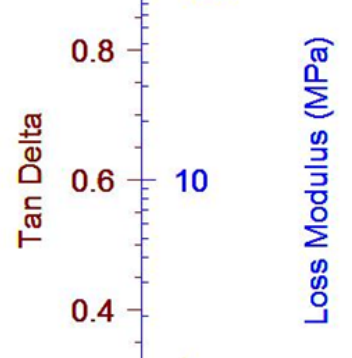

Sample: North Butyl 30 mil

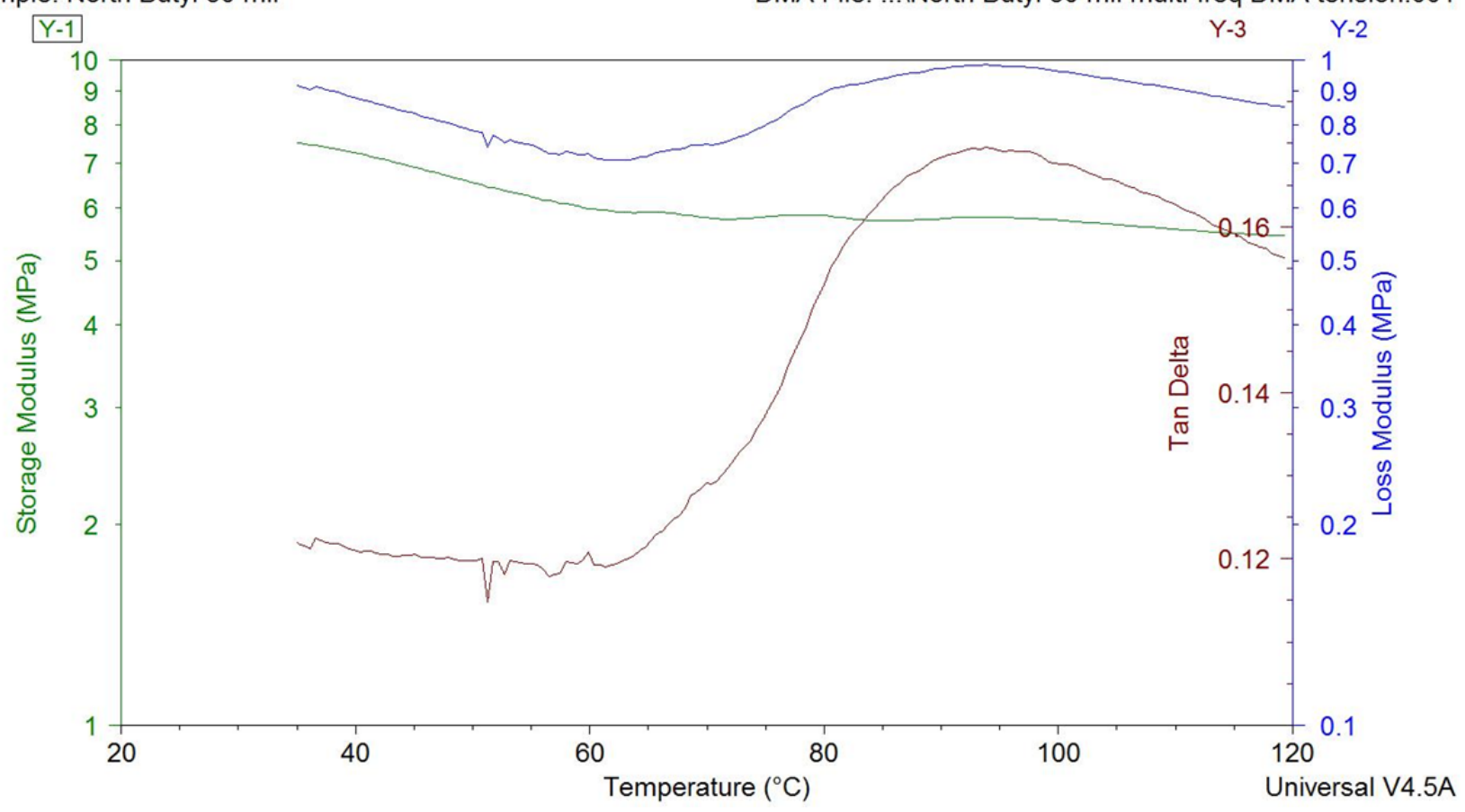


Sample: North Butyl 30 mil B

DMA File: C:.... Nina BreakironINorth Butyl 30 mil B.001

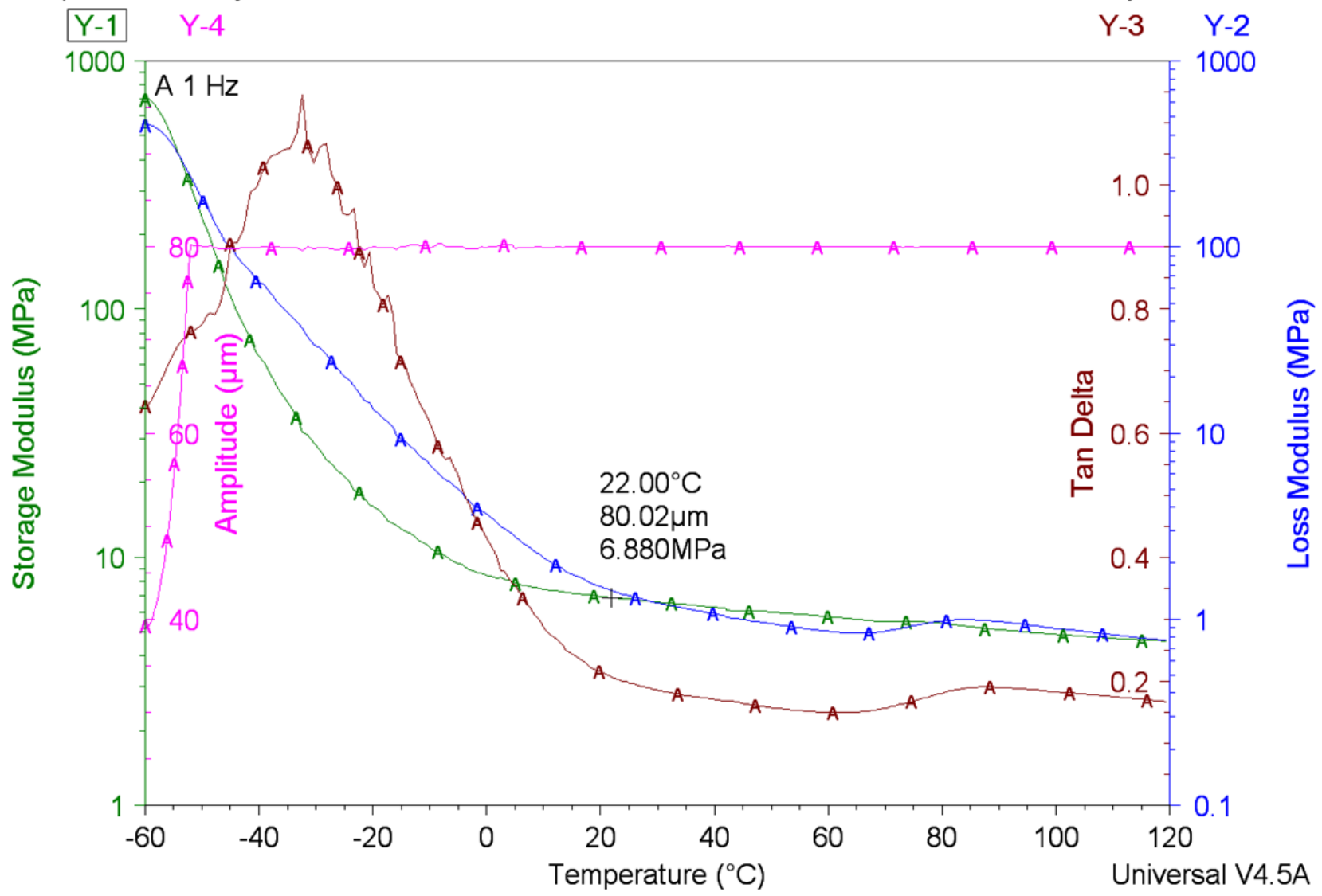

Sample: North Butyl 30 mil B

DMA File: F:IDMAINorth Butyl 30 mil B.001

$\mathrm{Y}-1$

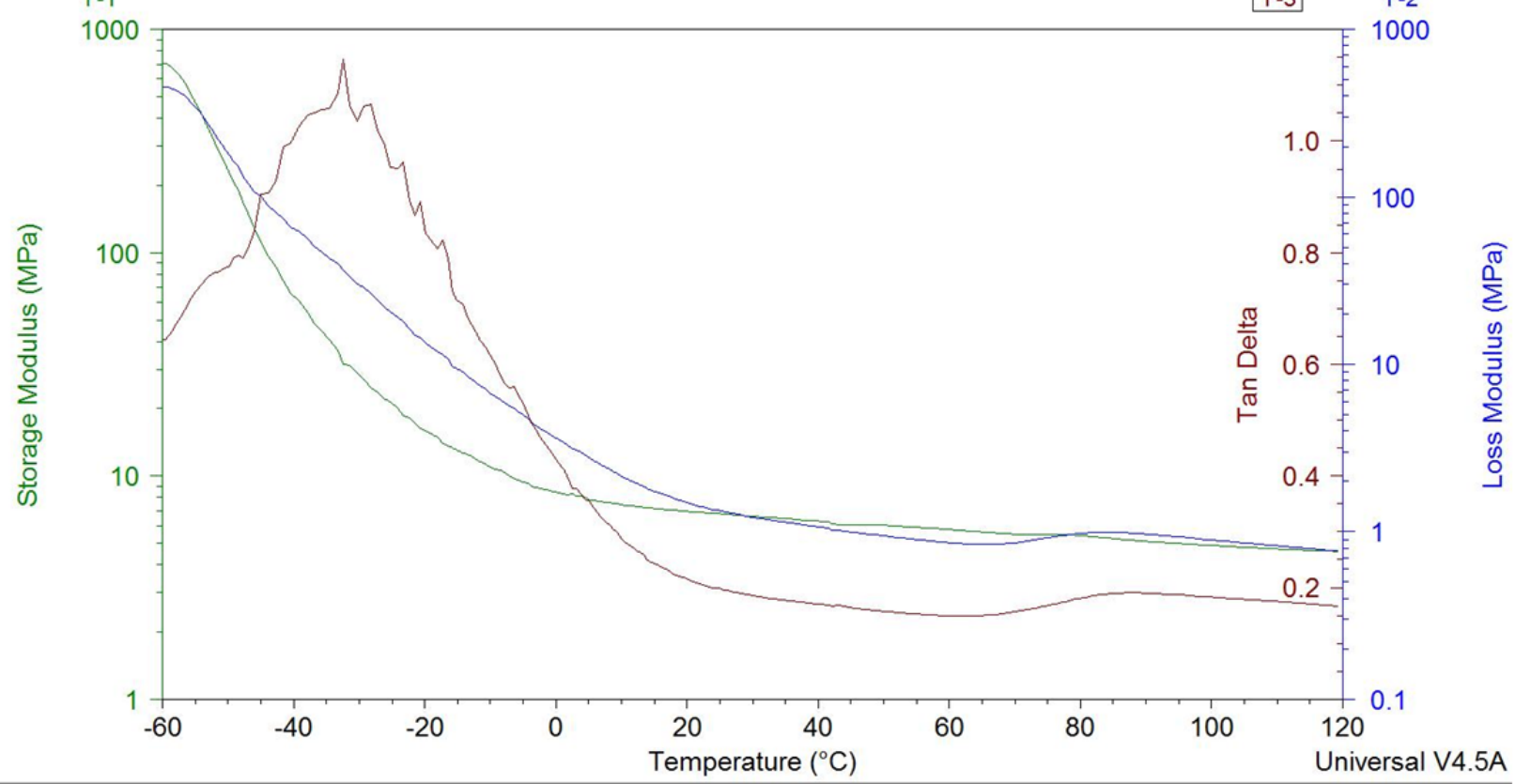


Sample: Piercan Butyl 15 mil A

DMA File: F:IDMAIPiercan Butyl 15 mil A.001

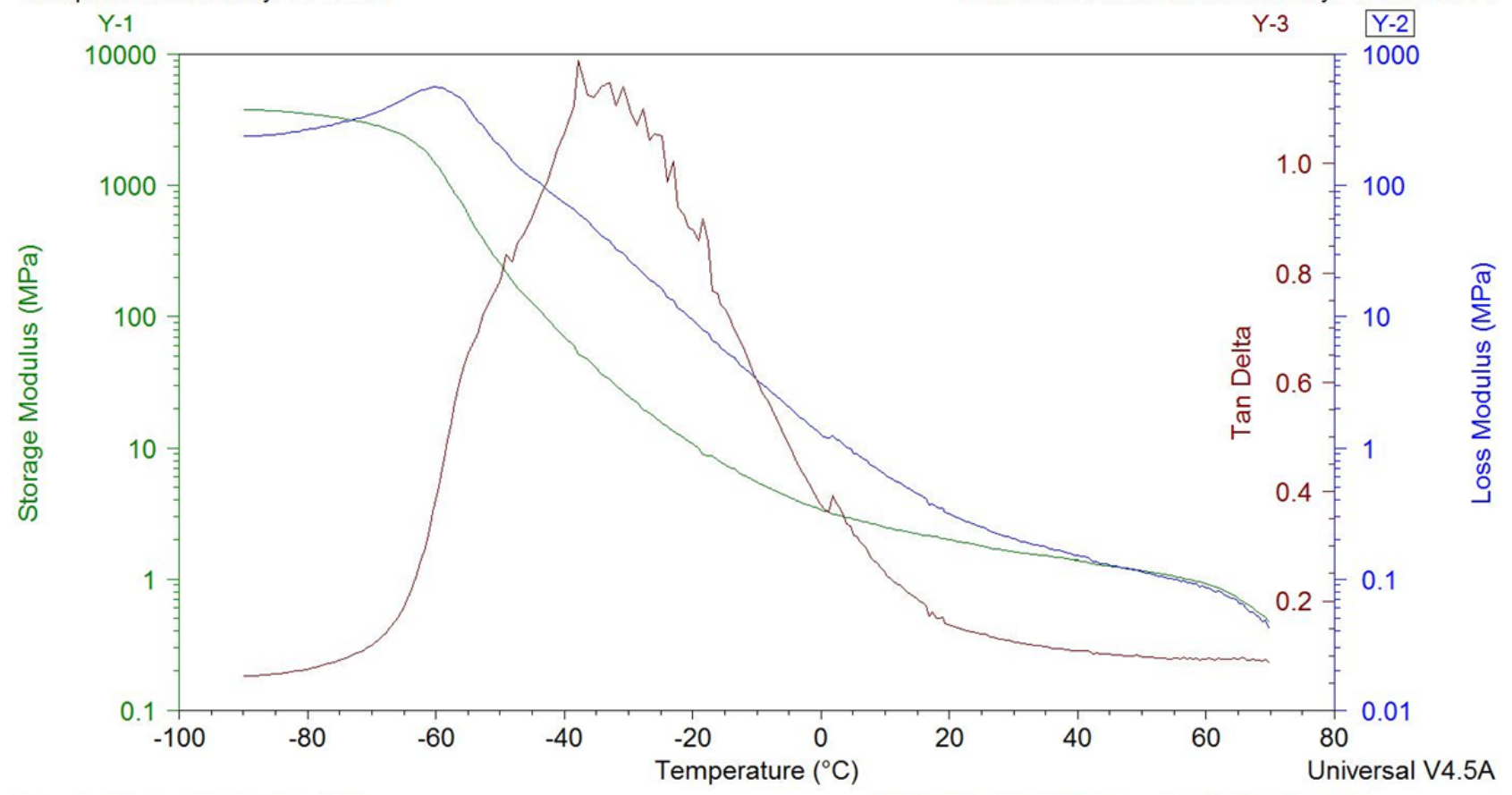

Sample: Piercan Butyl 15 mil B DMA File: F:IDMAIPiercan Butyl 15 mil B.001

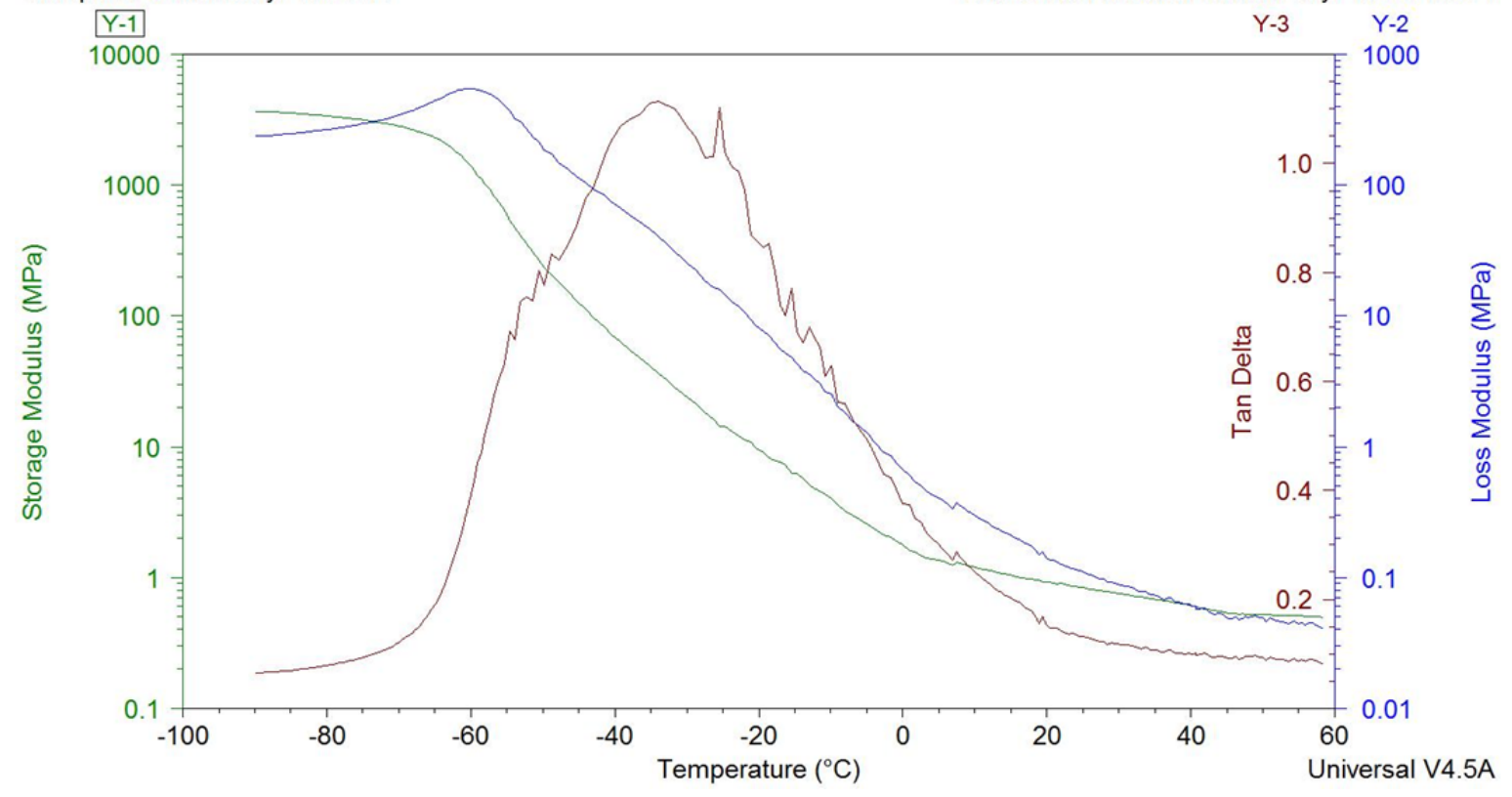


Sample: Piercan Butyl 15 mil C

DMA File: F:IDMAIPiercan Butyl 15 mil C.001

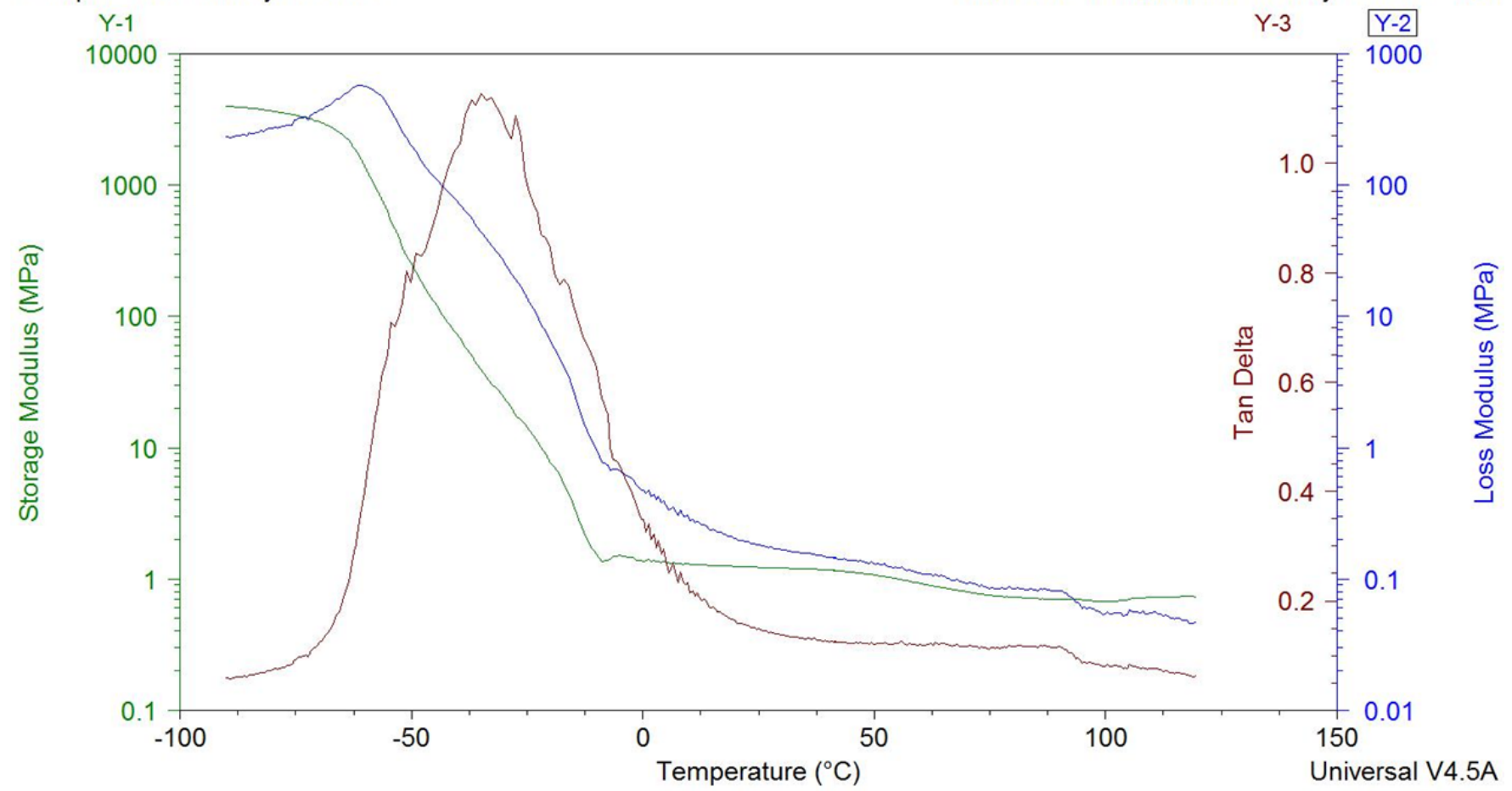

Sample: Piercan Butyl 30 mil A

DMA File: C.....IPiercan Butyl 30 mil A.001

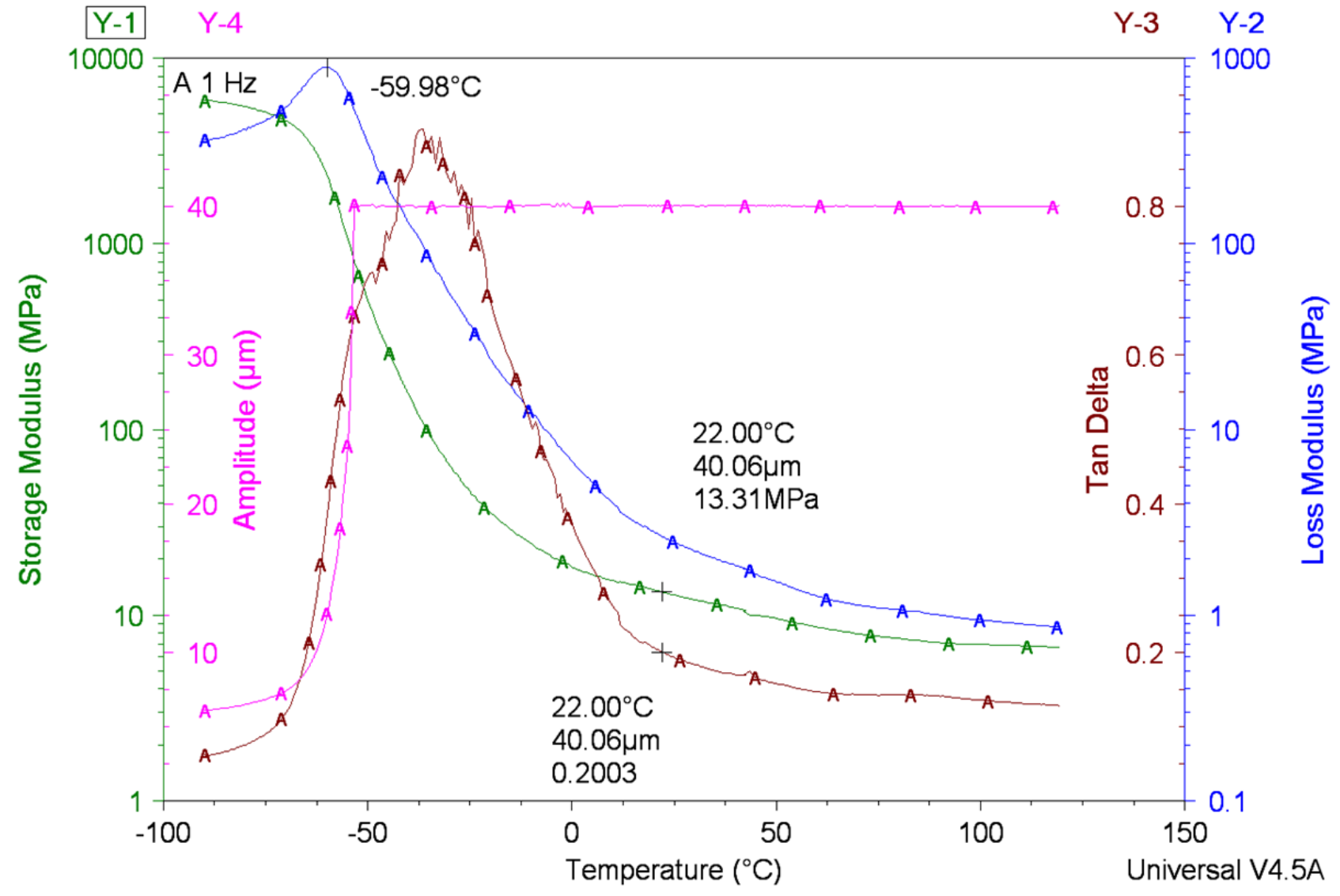




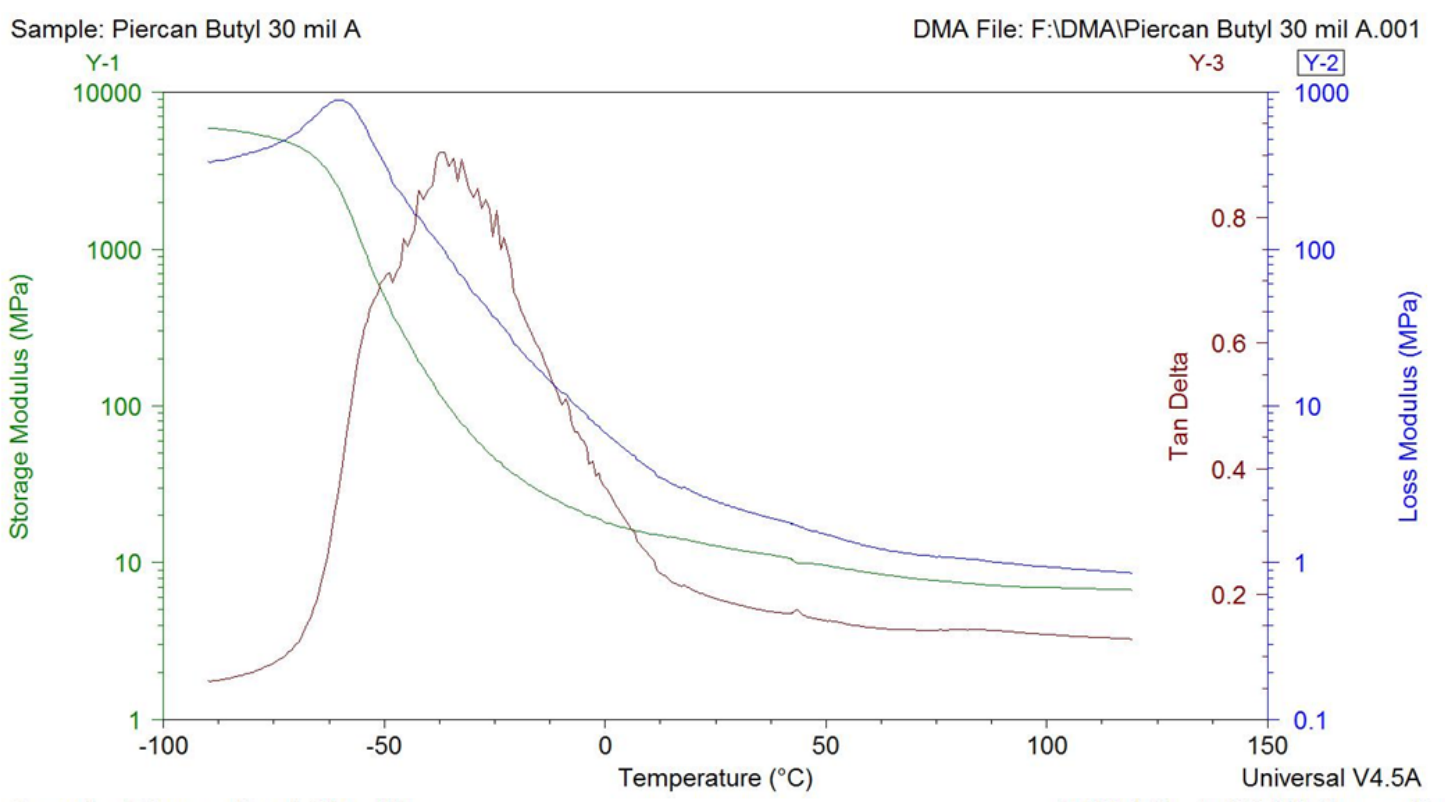

Sample: Piercan Butyl 30 mil B

DMA File: F:IDMAIPiercan Butyl 30 mil B.001

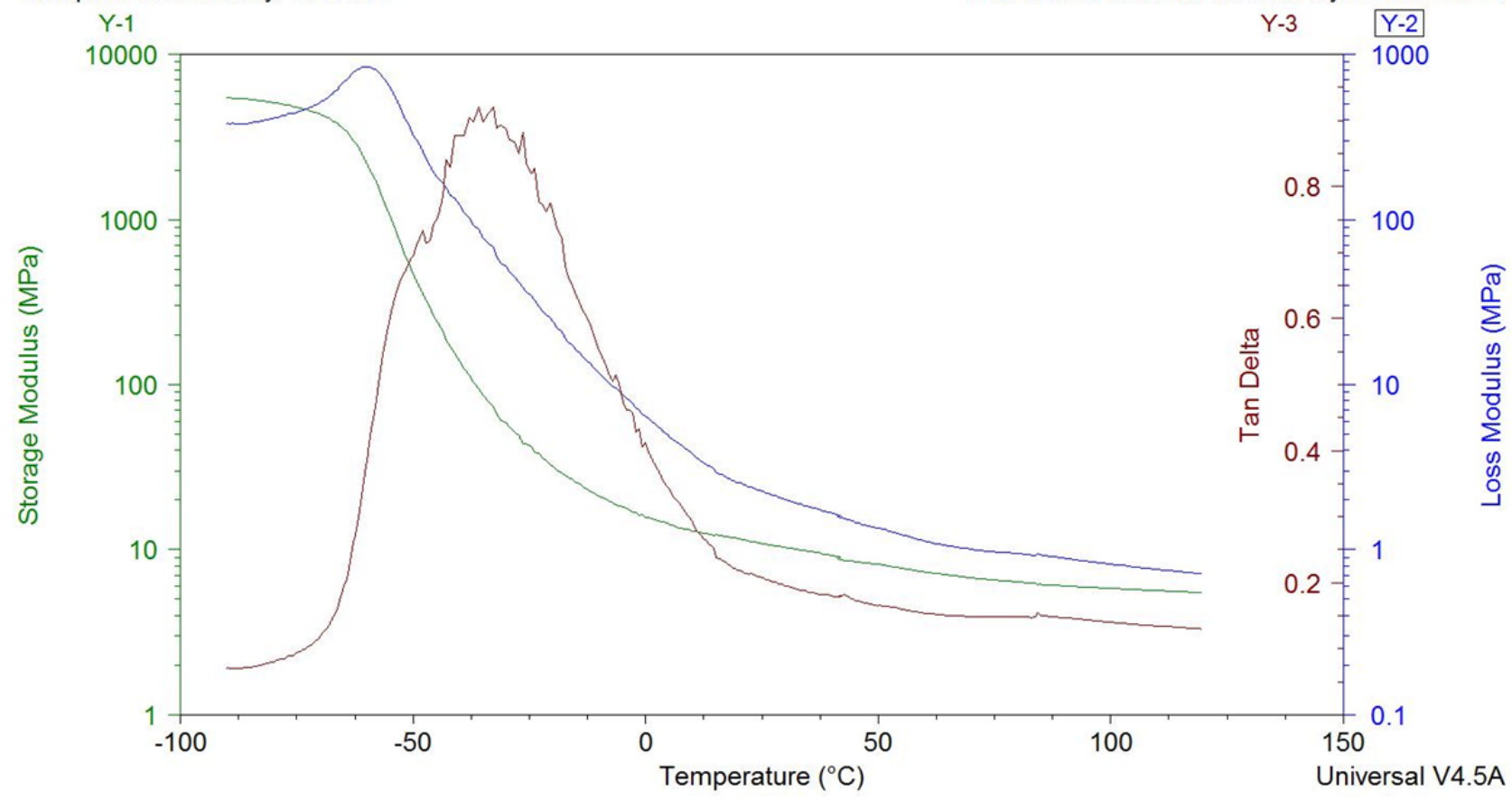


Sample: Piercan ESDB 15 mil A Y-1

0
त0
$\frac{0}{2}$
$\frac{0}{3}$
$\frac{0}{0}$
$\frac{0}{2}$
0
0
$\frac{10}{0}$
0

10000

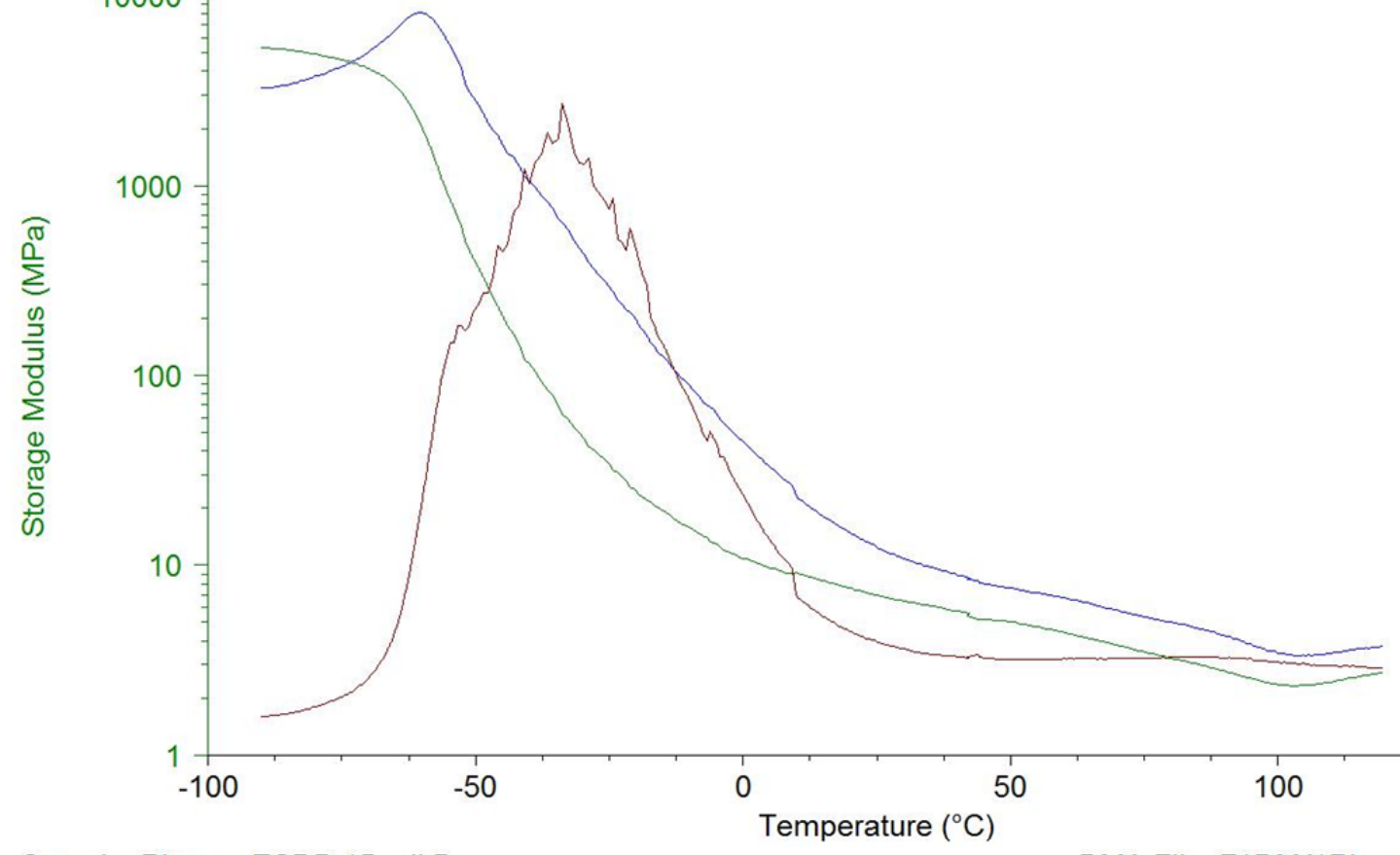

DMA File: F:IDMAIPiercan ESDB 15 mil A.001

DMA File: F:IDMAIPiercan ESDB 15 mil B.001

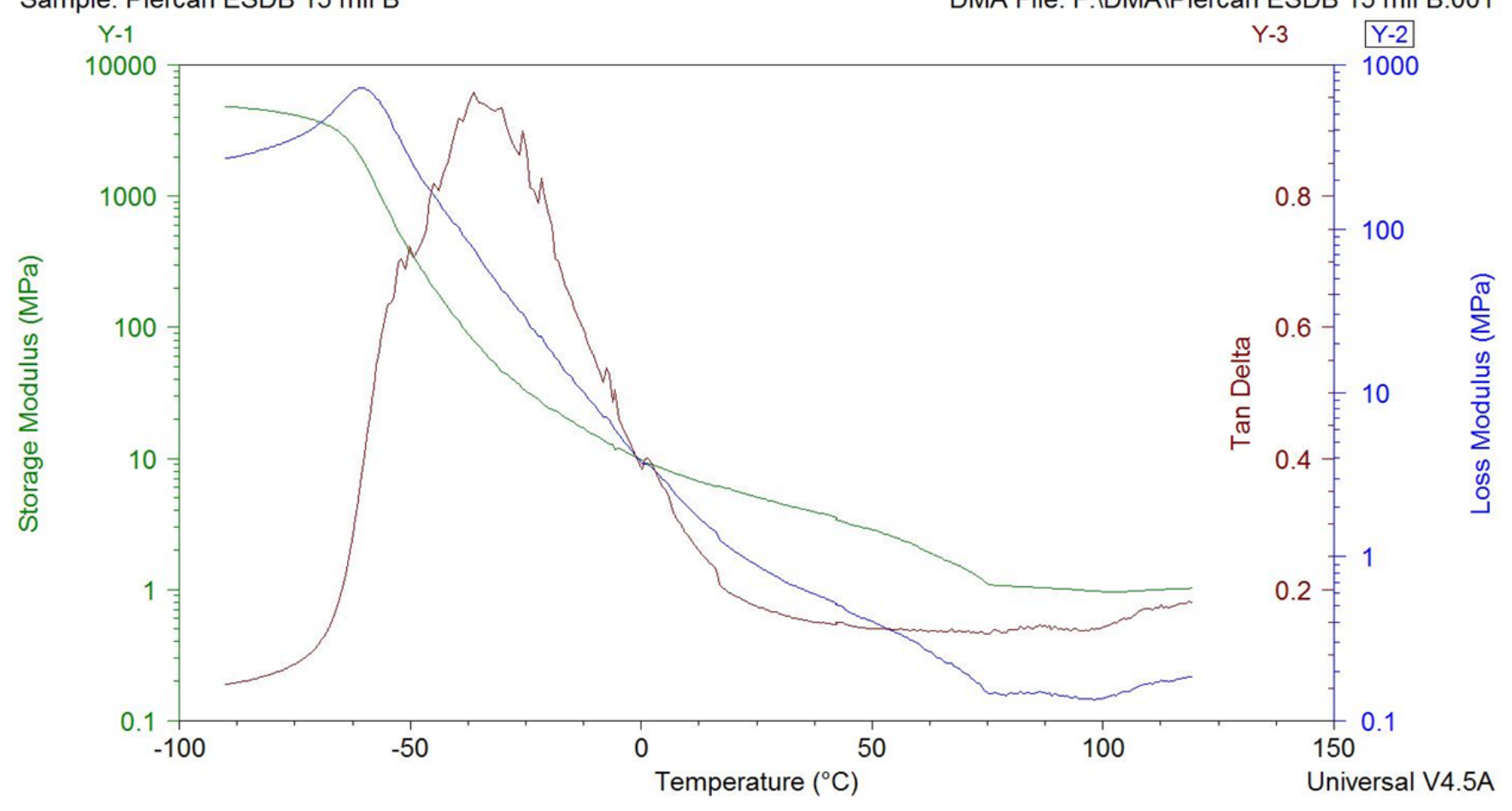


Sample: Piercan ESDB 24 mil A

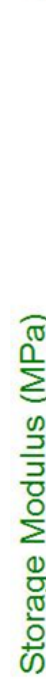

Y-1

$Y-1$

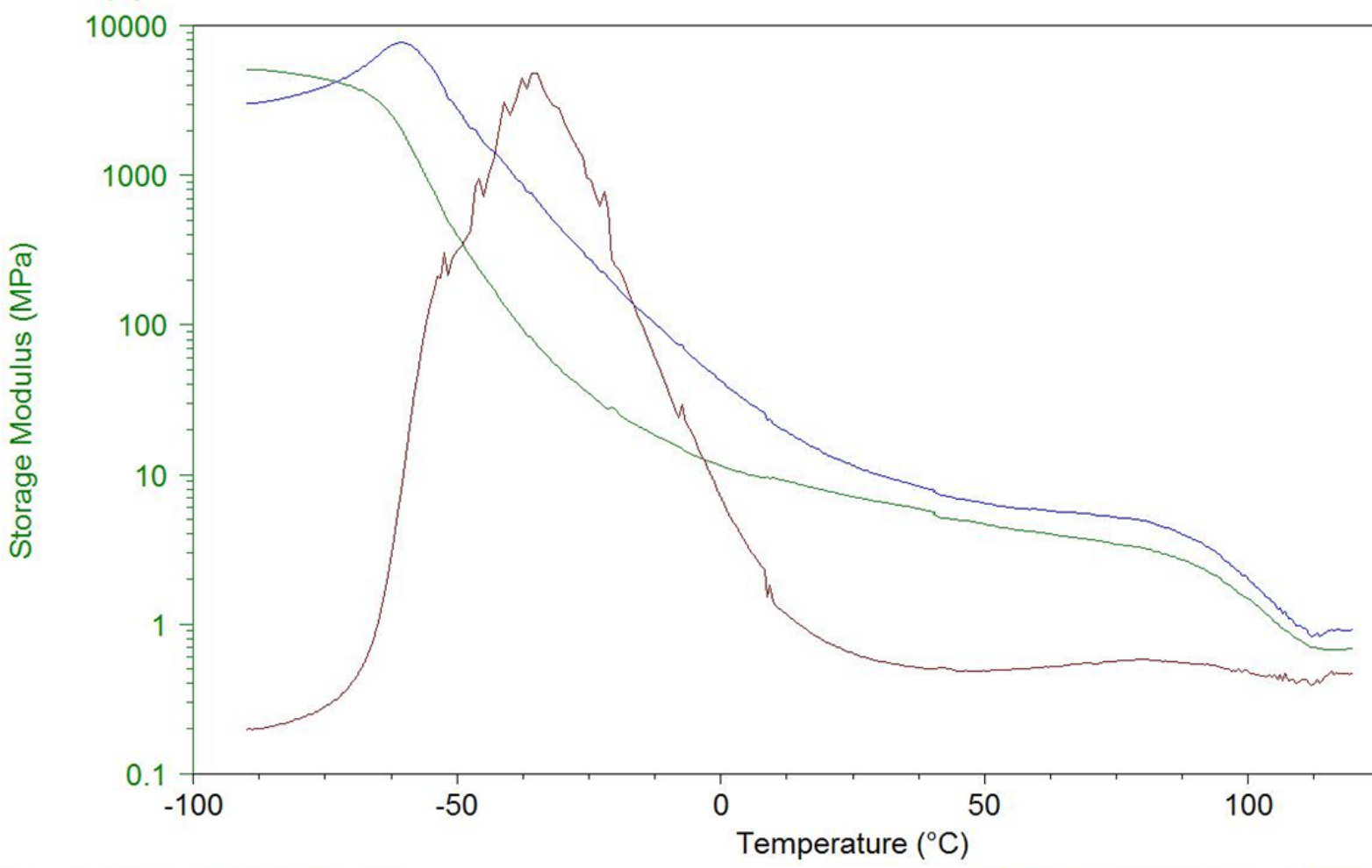

DMA File: F:IDMAIPiercan ESDB 24 mil A.

$Y-3$
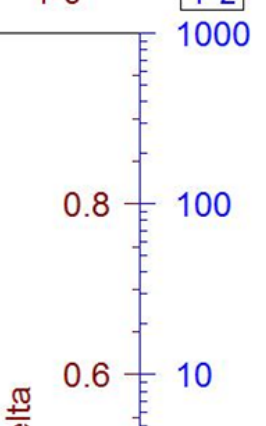

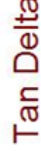
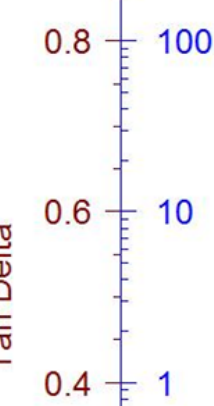

DMA File: F:IDMAIPiercan ESDB 24 mil B.001

Sample: Piercan ESDB 24 mil B

$\mathrm{Y}-1$

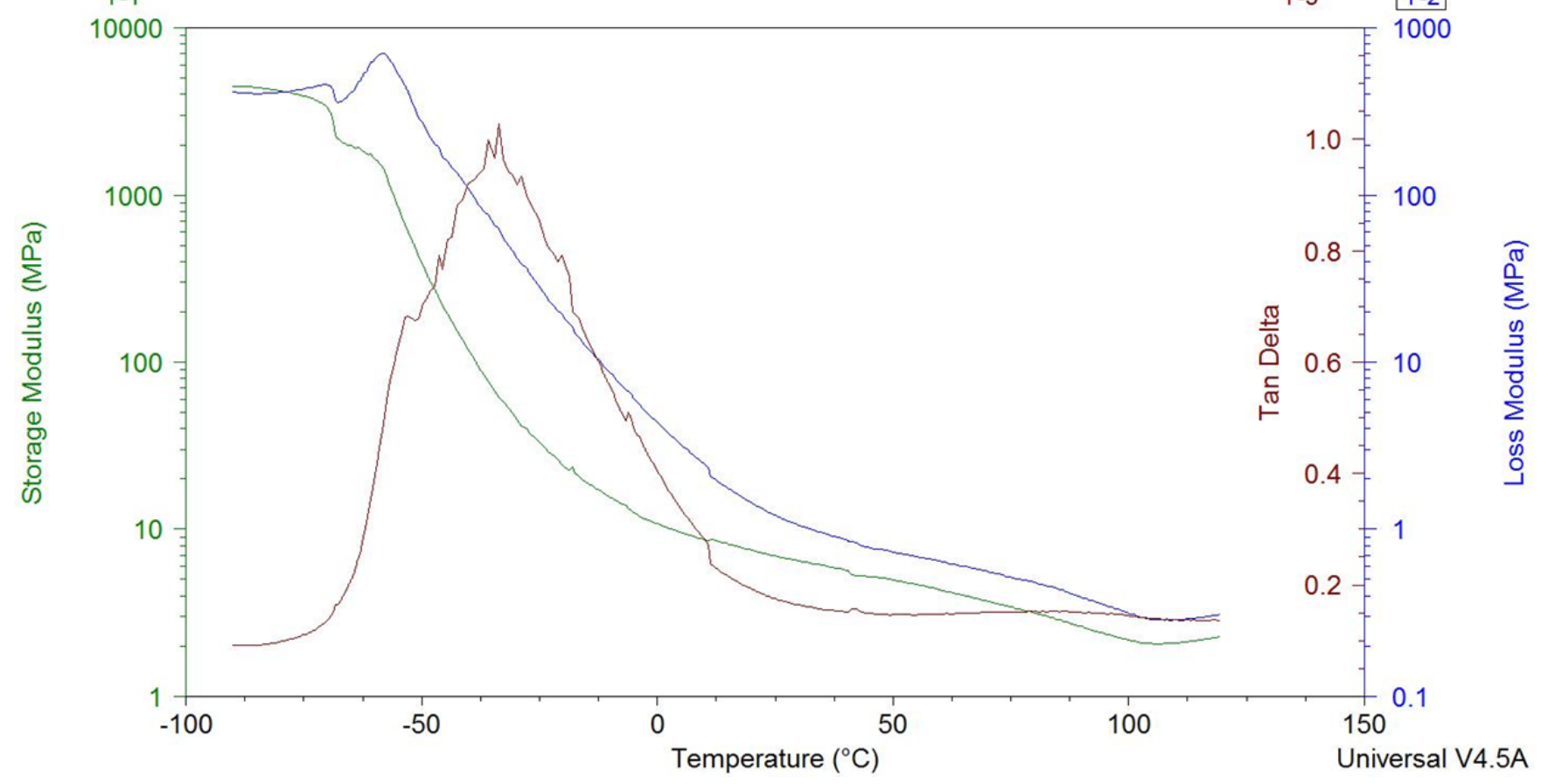


Sample: Piercan Hypalon 25 mil A

$\mathrm{Y}-1$

$$
\text { क }
$$$$
10000
$$

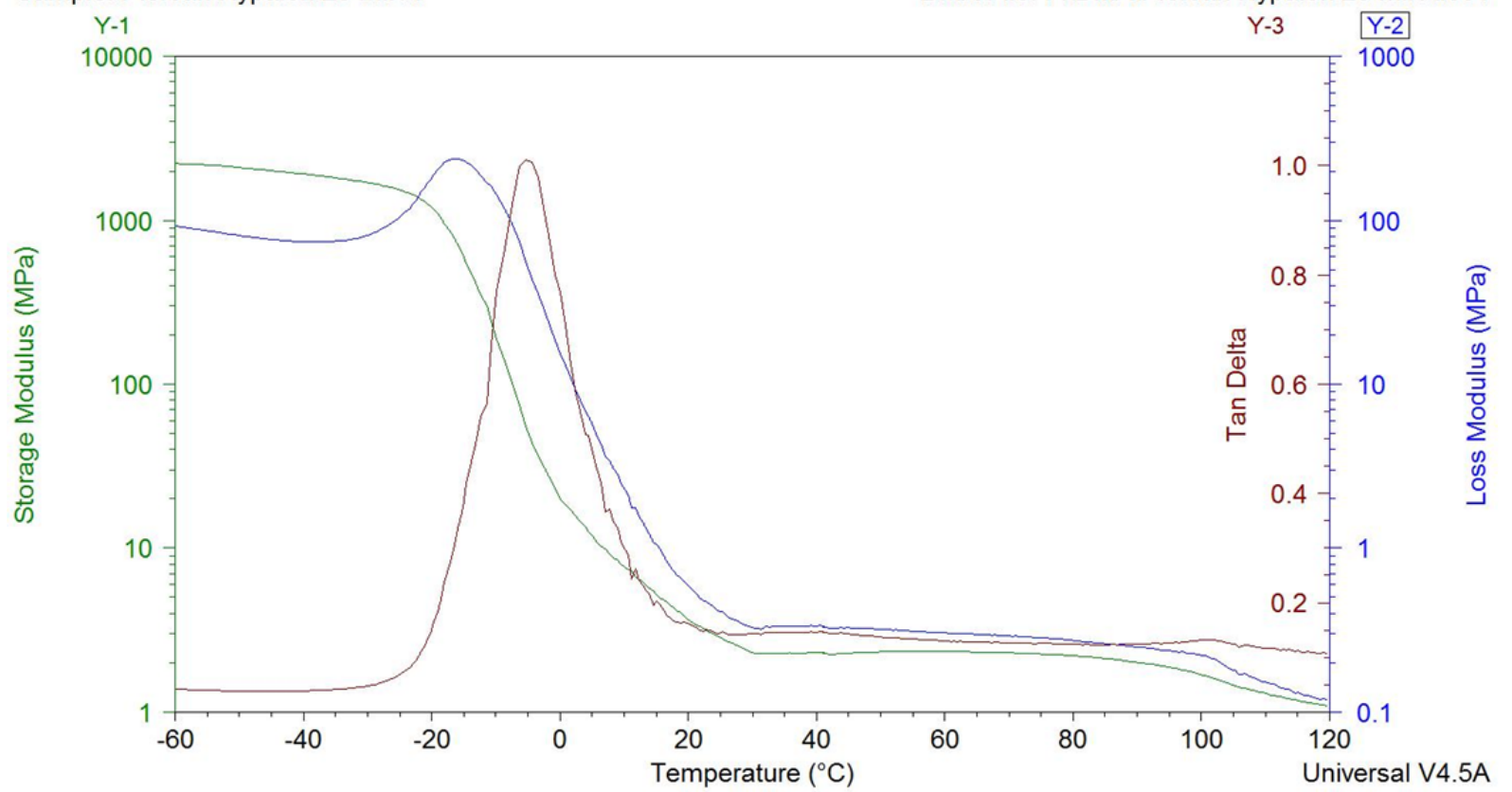

Sample: Piercan Hypalon 25 mil B Y-1

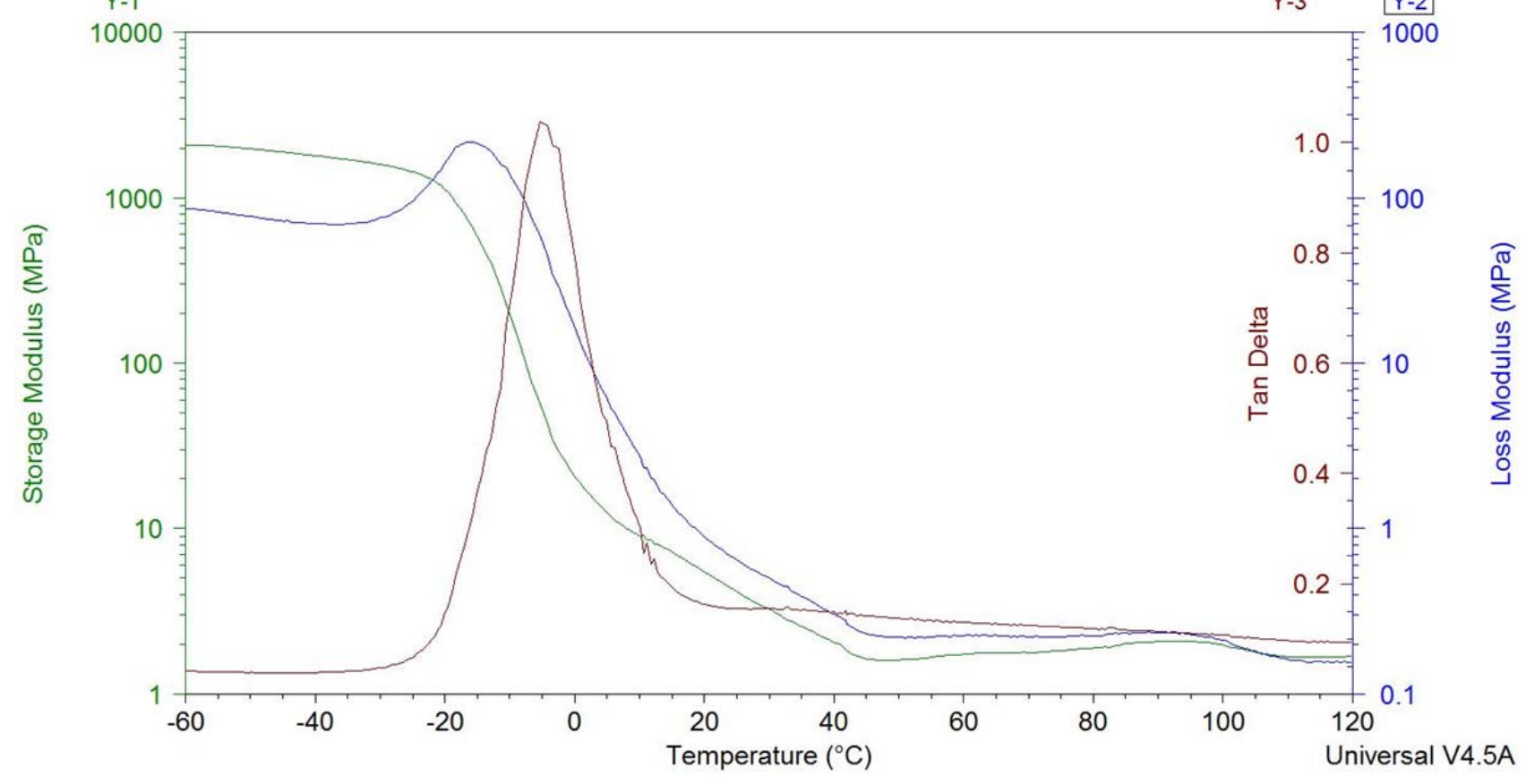

DMA File: F:IDMAIPiercan Hypalon 25 mil A.001

DMA File: F:IDMAIPiercan Hypalon 25 mil B.001

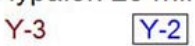


Sample: Piercan Polyurethane 15 mil A

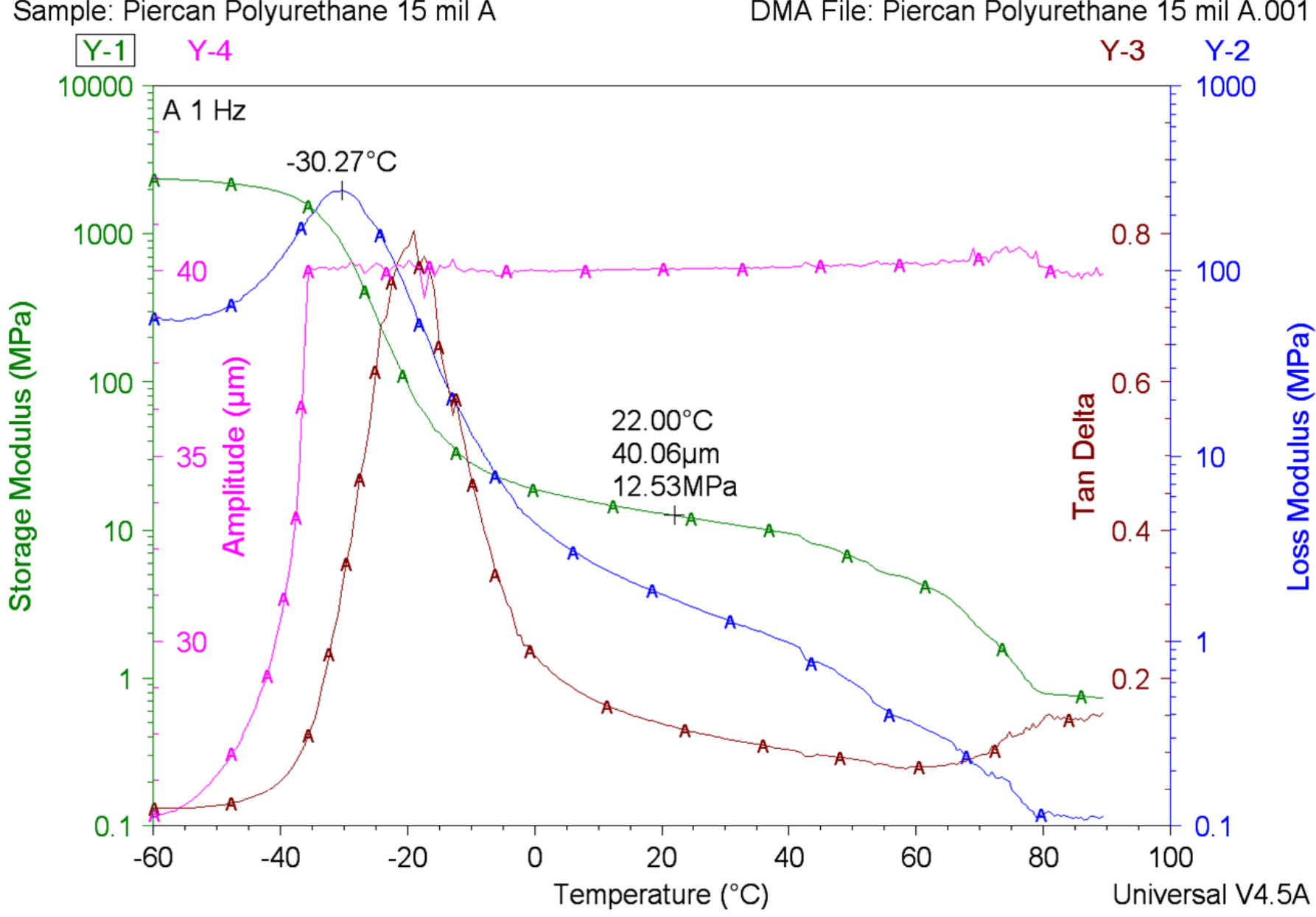

Sample: Piercan Polyurethane 15 mil A

DMA File: Piercan Polyurethane 15 mil A.001

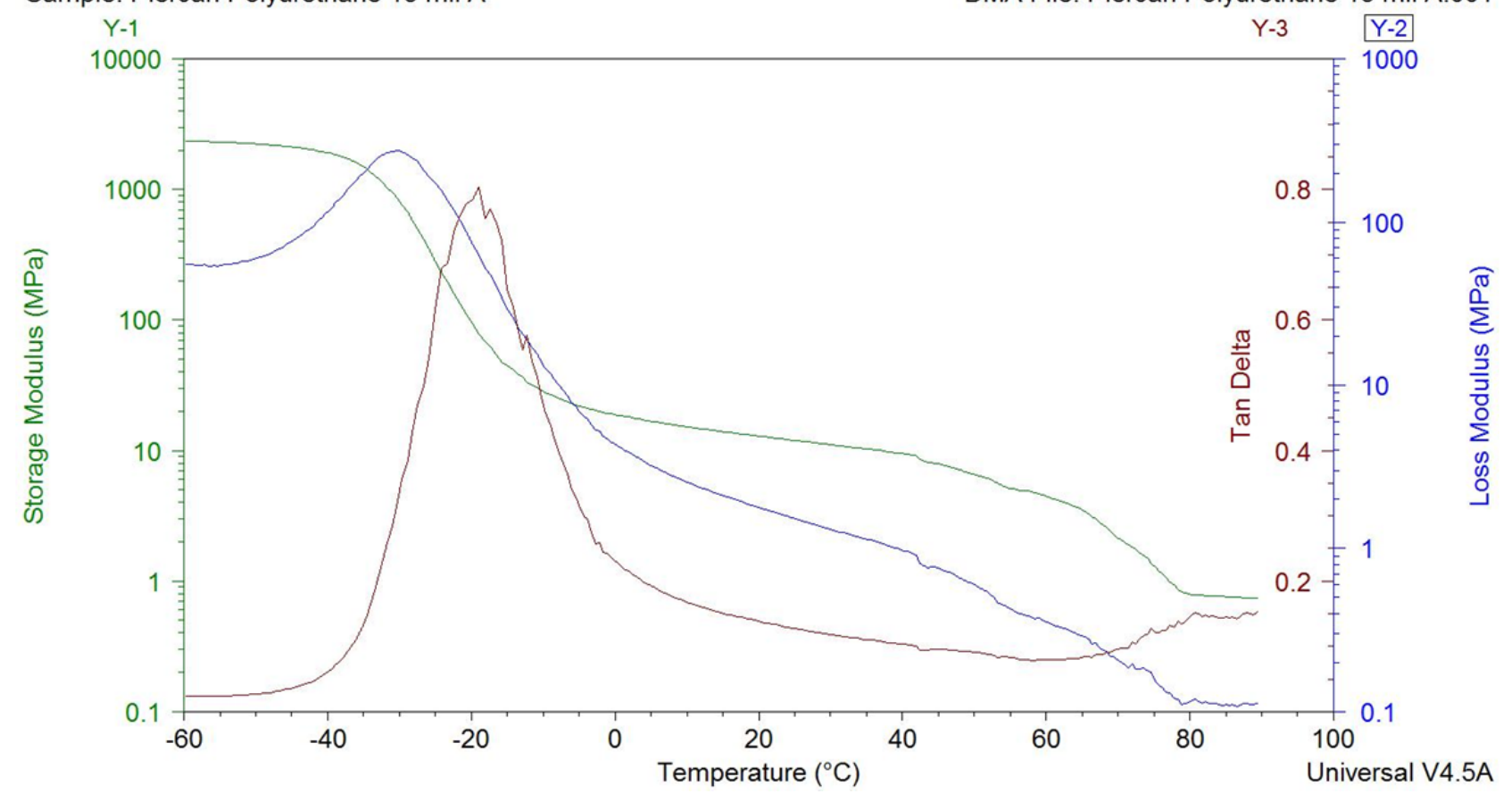


Sample: Piercan Polyurethane 15 mil B

DMA File: Piercan Polyurethane 15 mil B.001

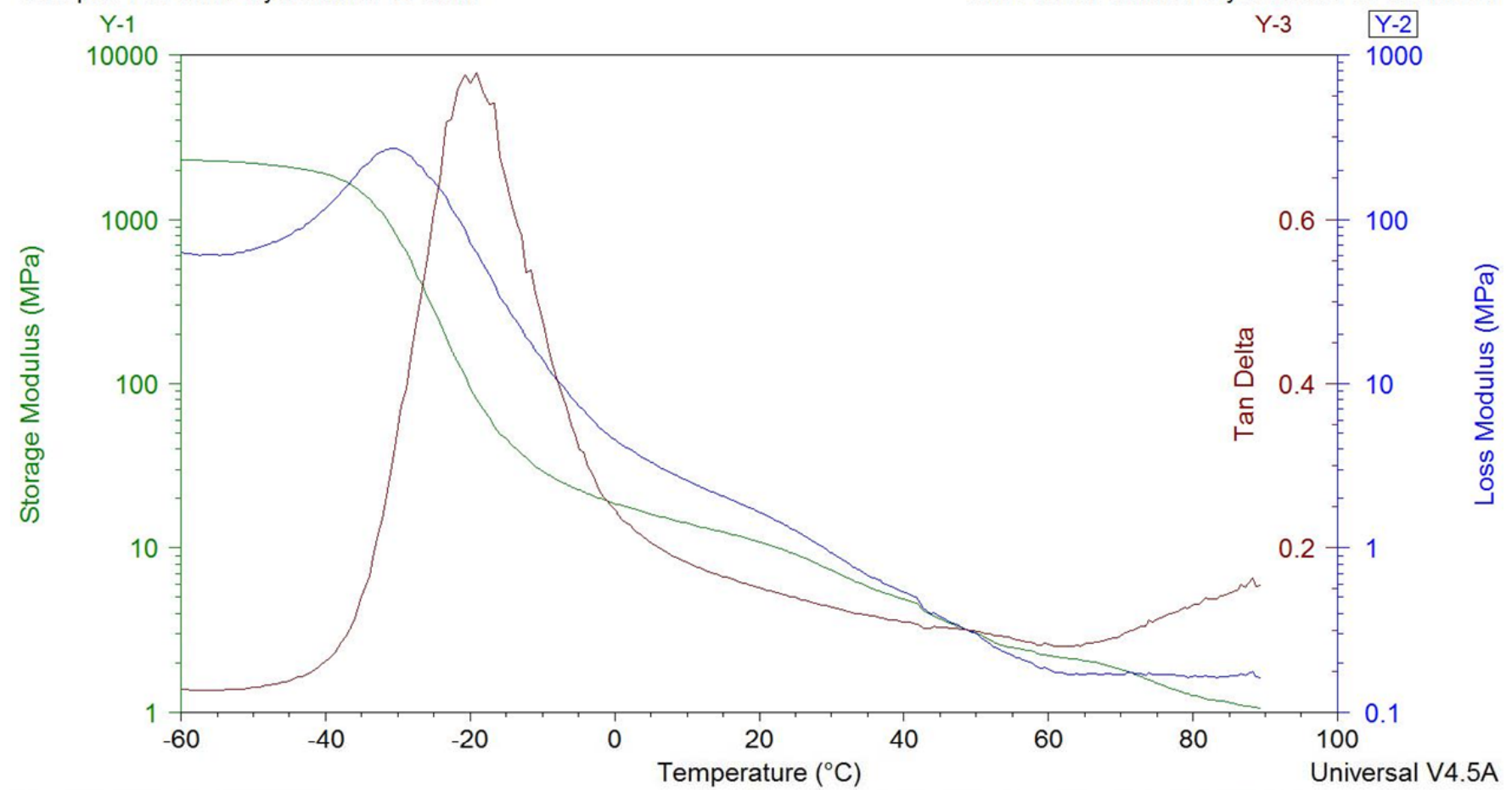

Sample: Piercan UY 20 mil A

DMA File: F:IDMAIPiercan UY 20 mil A.001

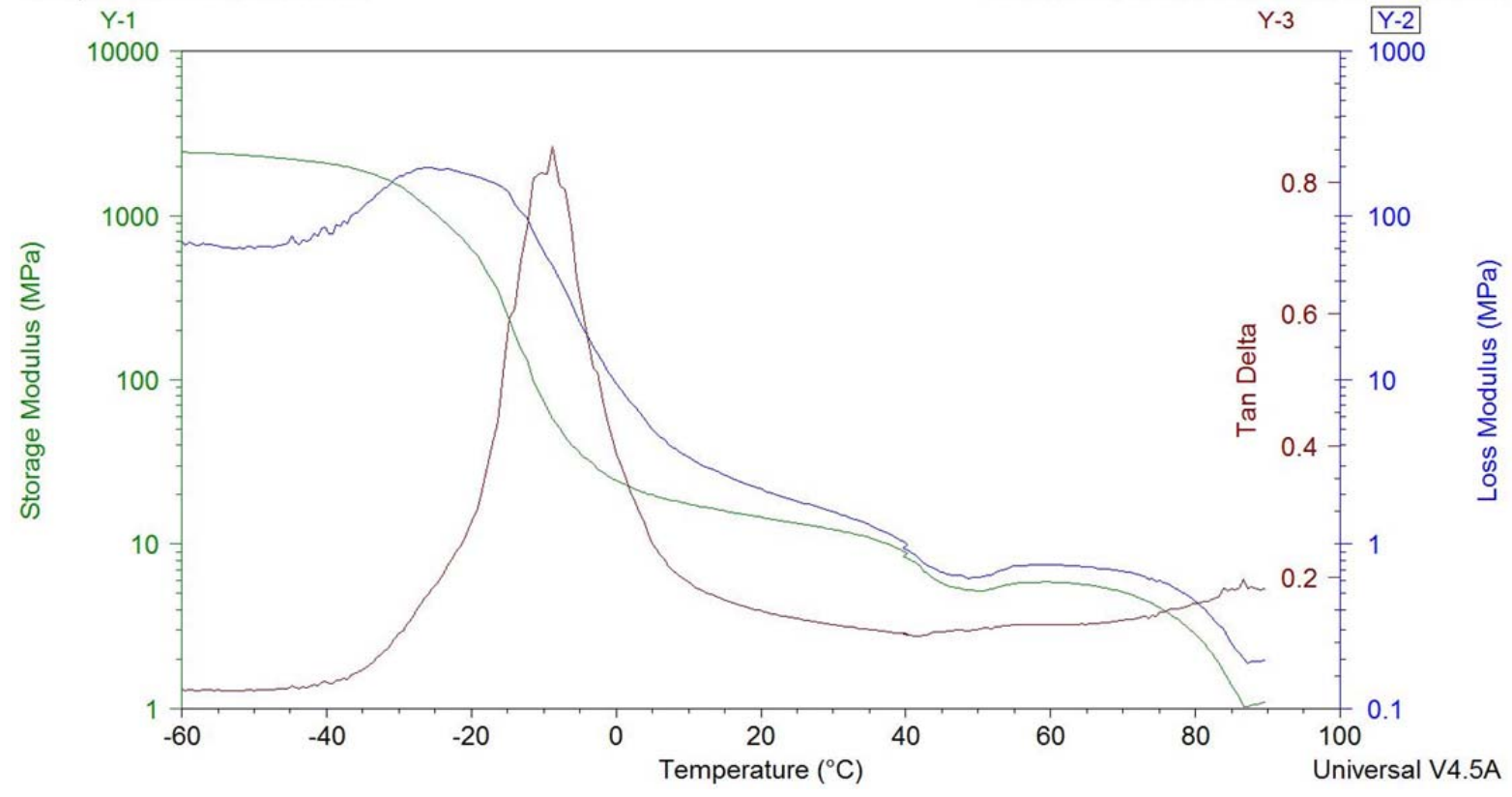




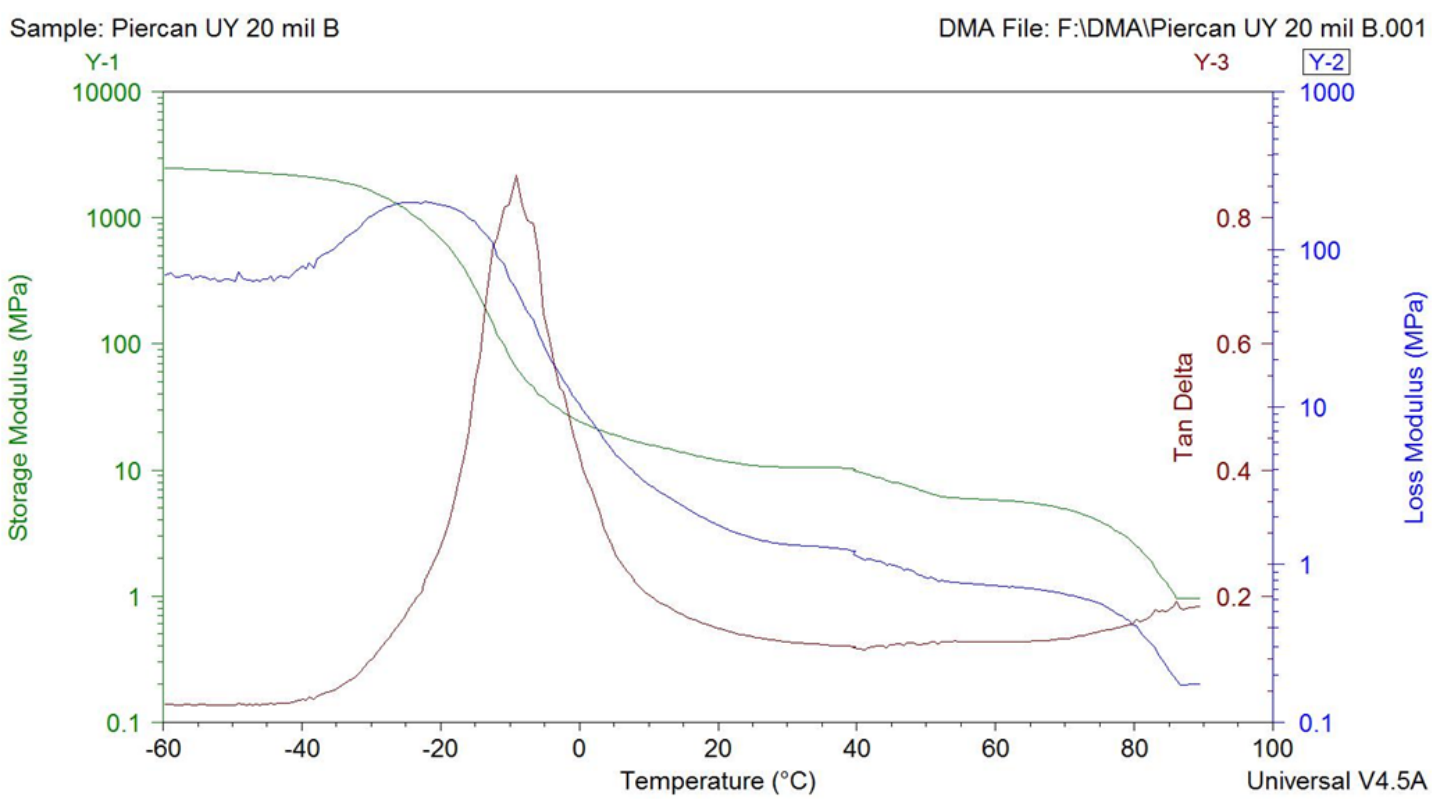

